\title{
Lactobacilli with probiotic potential in the prairie vole (Microtus ochrogaster)
}

\author{
Senait Assefa ${ }^{1}$, Kathleen Ahles ${ }^{1}$, Simone Bigelow ${ }^{1}$, J. Thomas Curtis² and Gerwald A. Köhler ${ }^{\text {** }}$
}

\begin{abstract}
Background: Recent research suggests integration of the intestinal microbiota in gut-brain communication which could lead to new approaches to treat neurological disorders. The highly social prairie voles are an excellent model system to study the effects of environmental factors on social behavior. For future studies on the role of probiotics in ameliorating disorders with social withdrawal symptoms, we report the characterization of intestinal Lactobacillus isolates with probiotic potential from voles.

Methods and results: 30 bacterial strains were isolated from the vole intestine and found to be distinct but closely related to Lactobacillus johnsonii using $16 \mathrm{~S}$ rRNA gene sequencing and Random Amplification of Polymorphic DNA fingerprinting. In vitro characterizations including acid and bile tolerance, antimicrobial effects, antibiotic susceptibility, and adherence to intestinal epithelial cells were performed to assess the probiotic potential of selected strains. Since previous studies revealed that mercury ingestion triggers social deficits in voles, mercury resistance of the probiotic candidates was evaluated which could be an important factor in preventing/treating these behavioral changes.
\end{abstract}

Conclusions: This study demonstrates that lactobacilli with probiotic potential are present in the vole intestine. The Lactobacillus isolates identified in this study will provide a basis for the investigation of probiotic effects in the vole behavioral model system.

Keywords: Lactobacillus johnsonii, Prairie vole, Probiotics, RAPD, Intestine, Mercury, Behavior

\section{Background}

Interest in the use of probiotic bacteria to enhance intestinal health in humans and animals has been growing in recent years. Probiotics are "live microorganisms that, when administered in adequate amounts, confer a health benefit on the host" [1]. At the beginning of the $20^{\text {th }}$ century, the Ukrainian bacteriologist Elie Metchnikoff [2] suggested that health benefits were associated with the ingestion of lactic acid bacteria such a Lactobacillus bulgaricus. At present, many intestinal probiotics belong to the genus Lactobacillus. Lactobacilli are aerotolerant gram-positive bacteria that form an important portion of the normal human microbiotas of the oral cavity [3], gastrointestinal tract [3, 4], and female genitourinary

\footnotetext{
*Correspondence: gerwald.kohler@okstate.edu

1 Department of Biochemistry and Microbiology, Oklahoma State University Center for Health Sciences, 1111 West 17th Street, Tulsa, OK 74107, USA

Full list of author information is available at the end of the article
}

tract [5-7]. Of the more than 150 [8] known species of lactobacilli, the "acidophilus complex" has received particular attention because of the reported probiotic properties of some members of this subgroup [9]. An example is the species Lactobacillus johnsonii. Several studies reported that L. johnsonii strains isolated from the human intestine undergo processes that are thought to be beneficial to human health, particularly in the areas of immunomodulation, pathogen inhibition, and cell attachment $[10,11]$. In addition, accumulating clinical and scientific evidence highlights the important role of probiotic lactobacilli in the bidirectional communication of the gut-brain-axis [12-14]. Studies in mice on $L$. rhamnosus JB-1 treatment have shown alteration in the central gamma-aminobutyric acid (GABA) expression and modulation of emotional behavior and depression [13]. At present, however, the mechanisms how probiotics such as $L$. johnsonii could affect brain function are unclear, but proposed mechanisms involve, e.g., the bacterial production of neurotransmitter precursors or of 
chemical compounds that act as hormones or that stimulate vagal afferent pathways $[13,15,16]$.

For the past two decades, prairie voles (Microtus ochrogaster) have been the dominant animal model in which to study the formation and maintenance of social affiliations $[17,18]$ and have been proposed as an important animal model in which to study disorders such as schizophrenia, autism, and the effects of traumatic brain injury, all of which negatively impact social functioning $[19,20]$. Prairie vole social behavior has been well-characterized. Field studies show that prairie voles are highly social; pairs share a nest and parental duties and, in fact, both members of a pair often are found in the same trap [21]. In the laboratory, voles appear to avoid isolation by seeking out conspecifics, and in fact, voles suffer significant stress when isolated [22-26]. In contrast to more traditional laboratory animals, prairie vole social behaviors actually are remarkably similar to those of humans, even displaying characteristics such as long-term pair-bonding, care of offspring by both parents, and sharing of a nest even beyond the breeding season [27]. Further, autonomic responses in voles are more like those of humans than they are like those of other rodent species [28]. Importantly, both the behavioral repertoire and the physiology of voles are well documented (e.g., [27, 29-32], so there is a strong literature base upon which additional studies can rest. Given their social structure, prairie voles present an ideal animal model in which to study the of the role of the microbiota-gut-brain-behavior axis in mediating social affiliation and avoidance behaviors, mate choice, parental care and other complex social interactions.

The primary objective of this study was to lay the groundwork for probiotic studies in voles by isolating Lactobacillus strains with high probiotic potential from the vole intestine. Host adaption is an important factor for probiosis. Therefore, we chose to isolate vole strains rather than using probiotics originating from humans or other animals. Lactobacilli were isolated using enrichment media and subsequently classified by $16 \mathrm{~S}$ rRNA gene sequencing which also allowed for PCR-based analyses of Lactobacillus abundance in the vole intestine. Since orally administered probiotics must survive passage through the highly acidic stomach and withstand the adverse intestinal environment, the strains' acid tolerance and bile resistance were determined. Further characteristics such as antimicrobial activities against fungi and bacteria as well as adhesion to intestinal epithelial cell lines were examined. In addition we included an assessment of the strains' resistance to mercury chloride. There is evidence that probiotic bacteria could bind many toxic compounds such as aflatoxin B1 [33], cyanotoxins [34], cadmium and lead [35-37] from environmental samples. In this study, the probiotic candidate strains' resistance to mercury chloride was also determined because research by Curtis and coworkers [38] revealed social withdrawal symptoms specifically in male voles upon inorganic mercury ingestion. Resistant strains might be more likely to survive mercury exposure and exert beneficial effects on an exposed host organism. All lactobacilli isolated from the vole intestine in this study were closely related to $L$. johnsonii and several of the isolated strains exhibited potential for probiotic properties.

\section{Results}

For purposes of characterizing the baseline state of vole gut lactobacilli, we have used same-sex cage mates. This eliminates the potential confounds of stress responses associated with social isolation or endocrine responses associated with reproductive activation, mating, and parental behavior [22-26]. Further research will be needed to assess whether and how the microbiota might change in pair-bonded and/or parental animals. Although these are important questions, they are beyond the scope of this paper, and will be addressed in subsequent studies.

\section{Isolation of Lactobacillus strains from the prairie vole intestine}

Plating of intestinal content from prairie voles on Lactobacillus enrichment media resulted in the selection of 30 bacterial isolates for further analysis. Sequence analysis of the respective PCR amplicons generated with the well-conserved 16S rRNA gene primers $8 \mathrm{~F}$ and 1491R revealed distinct but closely related matches (e.g. $98 \%$ at $100 \%$ coverage) with database entries of the $16 \mathrm{~S}$ rDNA of Lactobacillus johnsonii (Table 1; Additional file 1: Figure S1). The 16S rDNA sequences of strains PV012, PV021, and PV034 also were confirmed by genome sequencing results (see Additional file 1: Figure S1).

\section{Strain differentiation by RAPD analysis}

Due to their close relatedness, a RAPD typing technique was employed to genetically type the 30 prairie vole $L a c$ tobacillus isolates. To systematically examine the genetic fingerprints of the different strains, a set of three previously published RAPD primers (272, 277, and 287; [39]) was evaluated for differentiation of the bacterial strains. Primer 272 (see Table 2) was chosen for further analyses because it delivered the best discriminatory power by reproducibly amplifying five or more random DNA fragments ranging in size from approximately $180 \mathrm{bp}$ to $3000 \mathrm{bp}$ (Fig. 1). Twenty-seven of the 30 isolates share common bands at 175, 375, 1200 and 1500 bp (Fig. 1). In this regard, the RAPD fingerprinting was able to cluster genetically identical strains as well as differentiate distinct strains among the isolates. For instance, multiple 
Table 1 List of bacterial and fungal strains used in this study

\begin{tabular}{|c|c|c|c|}
\hline Species & Strains & Origin & References \\
\hline Candida albicans & SC5314 & Clinical isolate & {$[73]$} \\
\hline Escherichia coli & NovaBlue Singles & EMD millipore & http://www.emdmillipore.com \\
\hline Pseudomonas aeruginosa & PA01 & Clinical isolate & {$[74]$} \\
\hline Staphylococcus aureus & ATCC 25923 & Clinical isolate & http://www.atcc.org \\
\hline Lactobacillus spp. & PV010-PV019 & Vole cecum & This study \\
\hline Lactobacillus spp. & PV020-PV021 & Vole small intestine & This study \\
\hline Lactobacillus spp. & PV022-PV023 & Vole cecum & This study \\
\hline Lactobacillus spp. & PV024-PV027 & Vole colon & This study \\
\hline Lactobacillus spp. & PV028-PV031 & Vole small intestine & This study \\
\hline Lactobacillus spp. & PV032-PV035 & Vole cecum & This study \\
\hline Lactobacillus spp. & PV036-PV039 & Vole colon & This study \\
\hline Lactobacillus johnsonii & ATCC $33200^{\mathrm{a}}$ & Human blood isolate & http://www.atcc.org \\
\hline Lactobacillus reuteri & $\mathrm{RC}-14^{\mathrm{a}}$ & Human vaginal isolate & {$[75,76]$} \\
\hline Lactobacillus rhamnosus & $\mathrm{LGG}^{\mathrm{a}}$ & Human fecal isolate & {$[77]$} \\
\hline
\end{tabular}

PV prairie vole isolate

a Probiotic reference strain

Table 2 DNA oligonucleotide primers and hydrolysis probes used in this study

\begin{tabular}{|c|c|c|}
\hline Primer & $5^{\prime}$-Sequence-3' & References \\
\hline $8 \mathrm{~F}$ & $\begin{array}{l}\text { AGAGTTTGATCM } \\
\text { TGGCTCAG }\end{array}$ & {$[65]$} \\
\hline $1491 R$ & $\begin{array}{l}\text { ACGGCTACCTTGTT } \\
\text { ACGACTT }\end{array}$ & {$[65]$} \\
\hline RAPD 272 & AGCGGGCCAA & {$[39]$} \\
\hline $1391 R$ & GACGGGCGGTGTGTRCA & {$[78]$} \\
\hline GK1053F & ATGGCTGTCGTCAGCTCGT & Adapted from [79] \\
\hline GKUNI16STaqCCC & $\begin{array}{l}\text { VIC-AACGAGCGCAAC } \\
\text { CC-MGB }\end{array}$ & This study \\
\hline TaqLacF & $\begin{array}{l}\text { TGGAAACAGATG } \\
\text { CTAATACCG }\end{array}$ & {$[40,41]$} \\
\hline TaqLacR & $\begin{array}{l}\text { CGTCCATTGTGGAAG } \\
\text { АTTCССT }\end{array}$ & Adapted from $[40,41]$ \\
\hline GKLPV16STaq & $\begin{array}{l}\text { FAM-ACTGAGACACGGC } \\
\text { CC-MGB }\end{array}$ & This study \\
\hline
\end{tabular}

strains such as PV010, PV014-PV019 or PV011, PV021, PV023, PV024, PV026, PV027, PV031, PV033, PV036, PV038 and PV039 were found to possess identical RAPD fingerprints suggesting that the isolates were identical or if genetic heterogeneity exists among these isolates, it could not be discriminated by RAPD. Overall, RAPD analysis of the 30 isolates revealed nine distinct clusters (Fig. 2). Notably, eight strains (PV012, PV013, PV020, PV029, PV030, PV032, PV034, and PV035) produced patterns with unique PCR bands (Fig. 2). RAPD bands at $1200,650,450$, and $300 \mathrm{bp}$ are shared with the human $L$. johnsonii ATCC 33200 strain by 23, 8, 11, and 12 isolates, respectively. In general, the RAPD fingerprinting analysis was effective for rapid differentiation within the different isolates. L. rhamnosus GG was included as reference strain and showed almost no RAPD pattern similarities to the vole intestinal strains.

\section{Abundance of lactobacilli in the prairie vole GI tract}

We conducted a comparative survey to estimate the amount of lactobacilli present in male and female vole GI tracts by $16 \mathrm{~S}$ rRNA-based qPCR. Published Lactobacillus-specific 16S rRNA gene primers were adapted to ensure complementarity with the respective gene sequences of the 30 vole strains, i.e., primer TaqLacR (Table 2) differs in one base from the published oligonucleotide sequence [40, 41]. Additionally, hydrolysis probes were designed for Lactobacillus and broad-range bacterial (primers GK1053F-1391R; Table 2) qPCR assays. These assays allowed for determination of the relative abundance of Lactobacillus $16 \mathrm{~S}$ rDNA copy numbers in DNA isolated from vole stomachs, proximal and distal small intestines, ceca, and colons (Fig. 3). Interestingly, this assay revealed very high levels of lactobacilli in the stomachs (up to $47 \%$ ) and to lesser extend (up to $10 \%$ ) in the small intestines of some animals (see Fig. 3). Other animals exhibited far lower Lactobacillus abundance in the upper GI tract. In the distal GI tract (cecum and colon), lactobacilli appear to be generally less prevalent, accounting for less than $1 \%$ of the total $16 \mathrm{~S}$ rRNA. No statistically significant differences (ANOVA) were found in Lactobacillus abundance between the tested males and females at the respective gastrointestinal sites.

For purposes of characterizing the baseline state of vole gut microbiota, we have used same-sex cage mates. This 

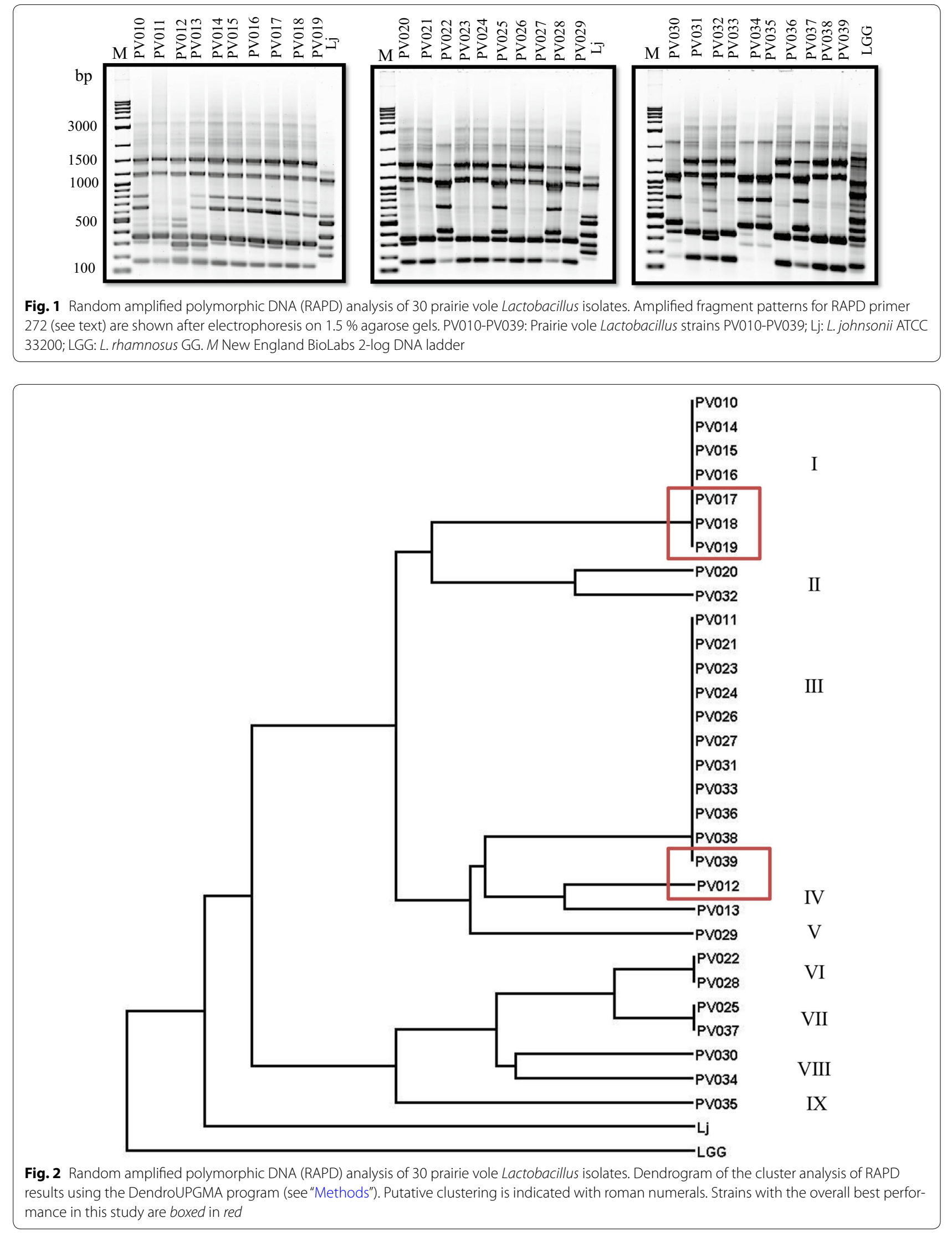


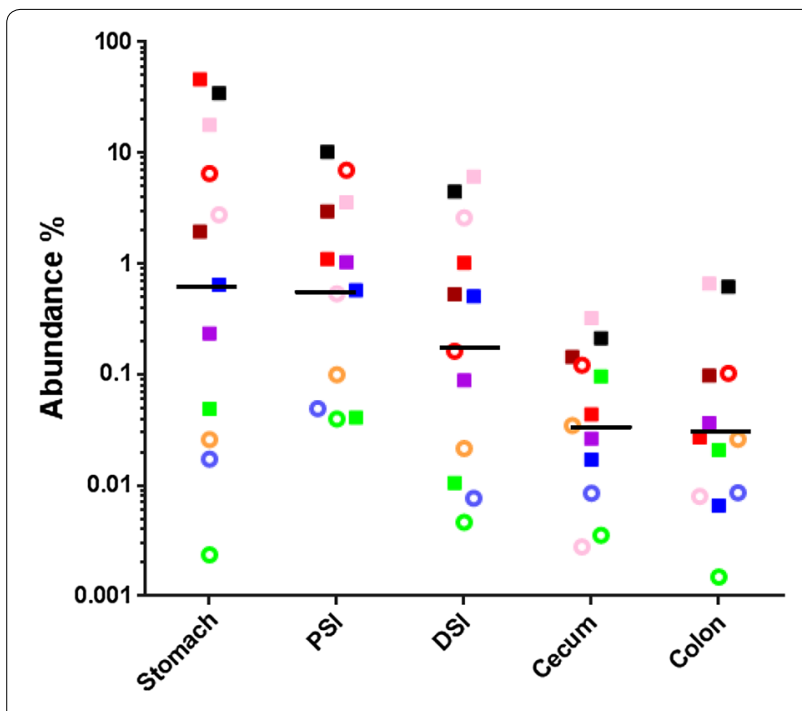

GI Tract Site

Fig. 3 Relative abundance of lactobacilli in the GI tract of prairie voles. As indicator for the amount of lactobacilli in the vole Gl tract, qPCR assays using group-specific and universal primers in conjunction with hydrolysis probes (see Table 2) were conducted to determine the relative abundance of Lactobacillus rRNA gene copies in content samples from the vole stomach, proximal small intestine (PSI), distal small intestine (DSI), cecum, and colon. Percent abundance values for five female (ring symbols) and seven male animals (solid symbo/s) are depicted on a logarithmic scale. Individual animals are represented by a specific symbol-color combination. Experiments were performed at least in duplicate. The horizontal bars indicate the geometric means of the abundance at the indicated sites for the twelve animals

eliminates the potential confounds of stress responses associated with social isolation or endocrine responses associated with reproductive activation, mating, and parental behavior [6-10]. Further research will be needed to assess whether and how the microbiota might change in pair-bonded and/or parental animals. Although these are important questions, they are beyond the scope of this paper, and will be addressed in subsequent studies.

\section{Acid tolerance of isolated Lactobacillus strains}

The 30 vole intestinal Lactobacillus strains were screened for tolerance to strongly acidic conditions. Nearly all strains survived an incubation period of $4 \mathrm{~h}$ at $\mathrm{pH} 3$, but only 17 strains were able to exhibit greater than $50 \%$ growth at this $\mathrm{pH}$ level (Fig. 4). Data of strains which did not perform well are not shown. Figure 4 shows percent growth calculated from acid resistance assays at $\mathrm{pH} 1-3$ during various incubation periods. The results indicated that the 17 selected strains survived during the $4 \mathrm{~h}$ incubation with some reduction in growth (20-44 \%) compared to the control at $\mathrm{pH}$ 7. Although greater than $50 \%$ of growth was suppressed, 12 of 17 strains survived $\mathrm{pH}$
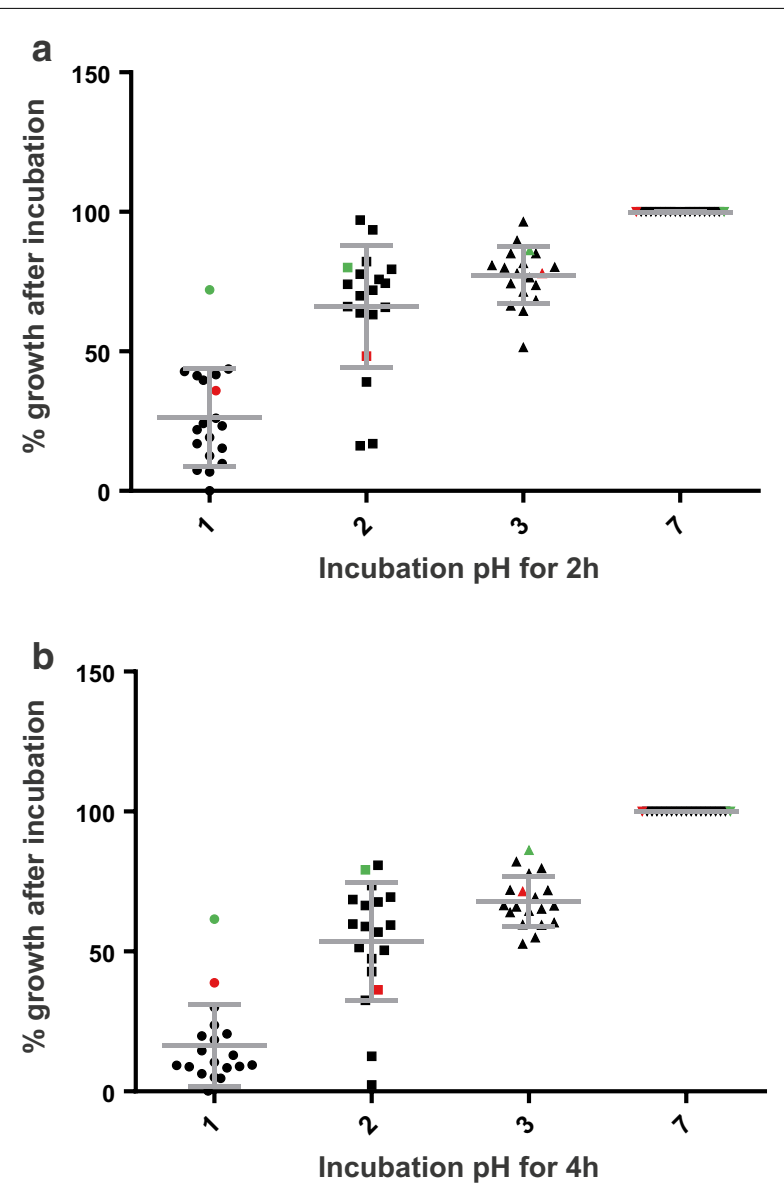

Fig. 4 Acid tolerance of vole intestinal Lactobacillus isolates. Lactobacilli were incubated for $2 \mathrm{~h} \mathrm{(a)} \mathrm{and} 4 \mathrm{~h}(\mathbf{b})$ at various $\mathrm{pH}$ levels ( $\mathrm{pH} 1, \mathrm{pH} 2, \mathrm{pH} 3$, and $\mathrm{pH} 7$ ) in PBS. Subsequently, the bacteria were inoculated in MRS and growth was determined after $24 \mathrm{~h}$ by $\mathrm{OD}_{600 \mathrm{~nm}}$ measurement. Results are shown for the 17 most acid-tolerant Lactobacillus isolates as percent growth relative to growth after incubation at pH 7 (set to $100 \%$ ). L. johnsonii ATCC 33200 (green data points) and L. rhamnosus GG (red data points) were included as reference strains. While all strains tolerated prolonged incubation at $\mathrm{pH} 3$ well, the depicted 17 strains survived $\mathrm{pH} 2$ and some even $\mathrm{pH}$ 1. The reference strains appear to be more acid tolerant at $\mathrm{pH} 1$ than the prairie vole strains. Data points are mean values from three experiments with duplicate measurements

2 and $\mathrm{pH} 1$ during the $4 \mathrm{~h}$ incubation. In general, little or no growth occurred in strains PV010, PV019, PV022, and PV037 following a $2 \mathrm{~h}$ incubation at $\mathrm{pH} 1$. The results show that the acid tolerance of the investigated strains was variable, but comparable to the probiotic reference strains L. johnsonii ATCC 33200 and L. rhamnosus GG (Fig. 4). Overall, L. johnsonii ATCC 33200 appeared to be the most acid resistant strain.

\section{Resistance to bile and the bile acid taurocholate}

Intestinal survival requires resistance to the antimicrobial components of bile. Therefore, the strains' susceptibility to 
bile and the bile acid taurocholate was examined. Among the 30 isolated strains only 10 (PV011-PV014, PV017PV019, PV021, PV024, and PV039) were resistant to high bile concentrations $(0.5-8 \%)$ within $24 \mathrm{~h}$ of exposure. Strain PV012 appeared to be the most resistant among these strains (Table 3 ) with an $\mathrm{IC}_{50}$ value of $4.2 \%$ bile (comparable to human L. johnsonii ATCC 33200), whereas

Table $3 \mathrm{H}_{2} \mathrm{O}_{2}$ production and $\mathrm{IC}_{50}$ values of human
and vole Lactobacillus strains for bovine bile, taurocho-
late, and $\mathrm{HgCl}_{2}$

\begin{tabular}{|c|c|c|c|c|c|}
\hline \multirow[t]{2}{*}{ Strain } & \multirow[t]{2}{*}{$\mathrm{H}_{2} \mathrm{O}_{2}^{\mathrm{a}}$} & \multirow{2}{*}{$\begin{array}{l}\text { Bovine bile } \\
(\%)^{b}\end{array}$} & \multirow{2}{*}{$\begin{array}{l}\text { Taurocholate } \\
(\mathrm{mmol} / \mathrm{L})^{\mathbf{b}}\end{array}$} & \multicolumn{2}{|c|}{$\mathrm{HgCl}_{2}(\mathrm{mmol} / \mathrm{L})^{\mathrm{b}}$} \\
\hline & & & & $24 \mathrm{~h}$ & $48 \mathrm{~h}$ \\
\hline PV010 & - & $<0.13$ & $7 \pm 0.3$ & $0.1 \pm 0.03$ & $0.1 \pm 0.00$ \\
\hline PV011 & - & $3.0 \pm 0.9$ & $>14$ & $0.1 \pm 0.01$ & $0.1 \pm 0.01$ \\
\hline PV012 & - & $4.2 \pm 0.3$ & $>14$ & $0.2 \pm 0.01$ & $0.2 \pm 0.04$ \\
\hline PV013 & - & $1.6 \pm 0.1$ & $>14$ & $0.1 \pm 0.03$ & $0.1 \pm 0.03$ \\
\hline PV014 & - & $1.8 \pm 0.8$ & $>14$ & $0.1 \pm 0.03$ & $0.1 \pm 0.03$ \\
\hline PV015 & - & $0.8 \pm 0.4$ & $>14$ & $0.1 \pm 0.03$ & $0.2 \pm 0.23$ \\
\hline PV016 & - & $<0.13$ & $7 \pm 1.2$ & $0.2 \pm 0.16$ & $0.2 \pm 0.23$ \\
\hline PV017 & - & $2.8 \pm 0.6$ & $>14$ & $0.2 \pm 0.07$ & $0.2 \pm 0.10$ \\
\hline PV018 & - & $3.3 \pm 0.7$ & $>14$ & $0.2 \pm 0.07$ & $0.2 \pm 0.11$ \\
\hline PV019 & - & $3.6 \pm 0.7$ & $>14$ & $0.1 \pm 0.03$ & $0.2 \pm 0.13$ \\
\hline PV020 & - & $<0.13$ & $>14$ & $0.2 \pm 0.22$ & $0.2 \pm 0.22$ \\
\hline PV021 & - & $0.4 \pm 0.3$ & 14 & $0.1 \pm 0.10$ & $0.2 \pm 0.22$ \\
\hline PV022 & - & $0.2 \pm 0.1$ & $9 \pm 2.3$ & $0.2 \pm 0.06$ & $0.2 \pm 0.24$ \\
\hline PV023 & - & $0.2 \pm 0.1$ & $10 \pm 3.5$ & $0.1 \pm 0.12$ & $0.2 \pm 0.15$ \\
\hline PV024 & - & $1.4 \pm 0.5$ & 14 & $0.1 \pm 0.05$ & $0.1 \pm 0.09$ \\
\hline PV025 & + & $<0.13$ & $5 \pm 1.2$ & $0.1 \pm 0.05$ & $0.2 \pm 0.23$ \\
\hline PV026 & - & $<0.13$ & $8 \pm 1.2$ & $0.2 \pm 0.27$ & $0.2 \pm 0.25$ \\
\hline PV027 & - & $<0.13$ & $8 \pm 1.7$ & $0.1 \pm 0.11$ & $0.2 \pm 0.12$ \\
\hline PV028 & - & $<0.13$ & $9 \pm 0.3$ & $0.1 \pm 0.09$ & $0.2 \pm 0.23$ \\
\hline PV029 & - & $<0.13$ & $9 \pm 1.7$ & $0.2 \pm 0.25$ & $0.2 \pm 0.25$ \\
\hline PV030 & + & $0.2 \pm 0.1$ & $10 \pm 2$ & $0.2 \pm 0.25$ & $0.2 \pm 0.26$ \\
\hline PV031 & - & $<0.13$ & $9 \pm 0.7$ & $0.1 \pm 0.08$ & $0.4 \pm 0.23$ \\
\hline PV032 & - & $0.13 \pm 0.1$ & $3 \pm 1.6$ & $0.3 \pm 0.20$ & $0.4 \pm 0.12$ \\
\hline PV033 & - & $0.2 \pm 0.1$ & $13 \pm 1.2$ & $0.2 \pm 0.18$ & $0.2 \pm 0.10$ \\
\hline PV034 & + & $0.2 \pm 0.1$ & $10 \pm 1.2$ & $0.1 \pm 0.08$ & $0.2 \pm 0.11$ \\
\hline PV035 & - & $0.3 \pm 0.2$ & $9 \pm 1.0$ & $0.3 \pm 0.16$ & $0.3 \pm 0.12$ \\
\hline PV036 & - & $<0.13$ & $8 \pm 3.9$ & $0.1 \pm 0.04$ & $0.1 \pm 0.05$ \\
\hline PV037 & + & $0.2 \pm 0.1$ & $10 \pm 2.3$ & $0.1 \pm 0.02$ & $0.4 \pm 0.07$ \\
\hline PV038 & - & $<0.13$ & $11 \pm 2.6$ & $0.2 \pm 0.14$ & $0.2 \pm 0.11$ \\
\hline PV039 & - & $0.8 \pm 0.2$ & $>14$ & $0.1 \pm 0.03$ & $0.2 \pm 0.05$ \\
\hline $\mathrm{Lj}$ & + & $4.0 \pm 0.8$ & $>14$ & $0.02 \pm 0.0$ & $0.02 \pm 0.0$ \\
\hline LGG & - & $1.0 \pm 0.1$ & $>14$ & $0.1 \pm 0.04$ & $0.2 \pm 0.11$ \\
\hline $\mathrm{RC} 14$ & + & n. d. & n. d. & n. d. & n. d. \\
\hline
\end{tabular}

a Purple color indicator for hydrogen peroxide production visible (+) or not visible (-) around colonies on ABTS agar

b IC50 values shown indicate the concentration of inhibitor (mean of triplicate experiments \pm standard deviations) that led to $50 \%$ growth reduction. For out of-out-range values the upper or lower concentration limits tested are shown. $L$. johnsonii ATCC $33200(\mathrm{Lj}), \mathrm{RC} 14$, and LGG are included as reference strains strain PV021 was the least resistant. The $\mathrm{IC}_{50}$ values for PV011, PV017-PV019 ranged between 2.7 and $3.6 \%$. The presence of $14 \mathrm{mmol} / \mathrm{L}$ taurocholate had no significant effect on the growth of eight strains (PV011-PV015, and PV017-PV019, see Table 3), but it significantly $(P<0.05)$ affected the growth rate of 14 strains (PV021-PV024, PV028-PV031, PV033, and PV034-PV039). Similar to the acid tolerance test, the bile and bile salt resistance levels of PV012 and PV017-PV019 were similar to the reference strains ATCC 33200 and LGG (Table 3).

\section{Resistance to mercuric chloride}

Lactobacilli have been suggested as candidate microorganisms that could aid in bioremediation and detoxification of heavy metals in the environment and in humans [37]. As a first step in the assessment of the capability of the investigated lactobacilli in mercury detoxification, we tested the strains' resistance to different mercury chloride concentrations. The $\mathrm{IC}_{50}$ values are summarized in Table 3 . Based on percentage growth at the initial $24 \mathrm{~h}$ incubation, most selected strains were found to be inhibited to $50 \%$ of control growth by concentrations $\geq 0.1 \mathrm{mmol} / \mathrm{L} \mathrm{of} \mathrm{HgCl}_{2}$. In some strains (e.g., PV037), longer incubation to $48 \mathrm{~h}$ revealed adaptive effects, i.e. an increase in the $\mathrm{IC}_{50}$ value, suggesting the induction of resistance mechanisms. Overall, these results indicated that the tested vole strains and LGG tolerated similar $\mathrm{HgCl}_{2}$ concentrations in growth media while strain ATCC 33200 exhibited at least five-fold lower resistance (Table 3).

\section{Inhibition of pathogens}

The antimicrobial activities of the vole Lactobacillus isolates were assessed by measuring the growth of the tester microorganisms Candida albicans, Escherichia coli, Pseudomonas aeruginosa and Staphylococcus aureus in the presence of the isolates' culture supernatants (Fig. 5). Supernatants from 11 vole isolates (PV012, PV017PV019, PV027, PV028, PV030, PV034, and PV037PV039) and the two reference strains (ATCC 33200 and LGG) showed strong antagonistic activities towards all four tester microorganisms. The growth of the bacteria was inhibited at only $1 / 8$ th ( 25 in $200 \mu \mathrm{L}$ total volume) dilution of these strains' culture supernatants. Conversely, the growth of $C$. albicans was also inhibited by these strains, however, only at more elevated supernatant concentrations. In contrast to C. albicans and S. aureus, E. coli, and P. aeruginosa do not grow well in pure MRS broth. Therefore, we used LB broth to grow these bacteria and also tested whether addition of up to $50 \%$ MRS would negatively influence growth. Compared to pure LB, growth of the bacteria was not significantly affected by addition of MRS broth alone (data not shown). 

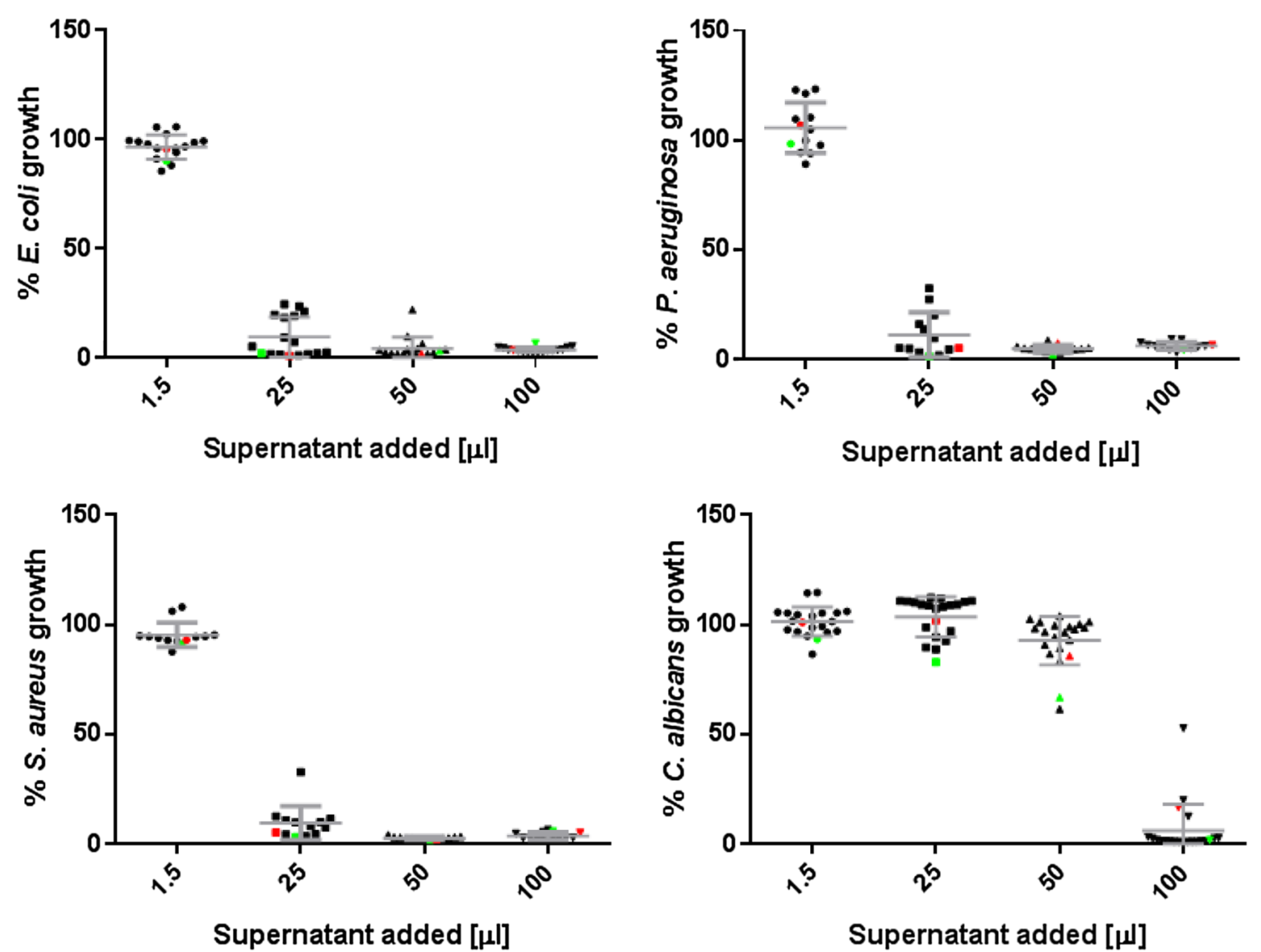

Fig. 5 Antimicrobial effects of culture supernatants from vole Lactobacillus strains. Growth inhibition of C. albicans, E. coli, P. aeruginosa, and S. aureus in presence of the supernatants of the probiotic strains L. rhamnosus GG (LGG), L. johnsonii ATCC 33200 (Lj), and eleven selected strains of vole lactobacilli is depicted. Graphs depict the percent growth of the indicator microorganisms in $200 \mu \mathrm{L}$ total culture volume following addition of 1.5, 25, 50 and $100 \mu \mathrm{L}$ of Lactobacillus culture supernatants. Percent values were calculated from control growth, i.e., no supernatant added to the culture. Assay results are graphed for the most efficient strains in inhibiting bacterial growth. In general, antifungal activities towards $C$. albicans were less potent and only effective at high supernatant concentrations. Data points are mean values from three experiments with duplicate measurements. $L$. johnsonii ATCC 33200 (green data points) and L. rhamnosus GG (red data points) were included as reference strains

\section{$\mathrm{H}_{2} \mathrm{O}_{2}$ production}

The thirty vole Lactobacillus isolates and the reference strains ATCC 33200, LGG and RC-14 were evaluated for peroxide production on ABTS/peroxidase indicator plates. Among the 30 isolates, four were found to produce the potential antimicrobial factor $\mathrm{H}_{2} \mathrm{O}_{2}$ under the assay conditions. The colonies of PV025, PV030, PV034, and PV037 and ATCC 33200 as well as the reference strain RC-14 generated purple coloration on the plates indicating hydrogen peroxide production $(+$, Table 3 ; Fig. 6). Colonies from the remaining strains, including LGG, did not produce any detectable $\mathrm{H}_{2} \mathrm{O}_{2}$ in this assay (-). Anaerobic incubation of the four $\mathrm{H}_{2} \mathrm{O}_{2}$ producers precluded color formation.

\section{Biofilm formation}

A crystal violet staining assay [42] was employed to test the 30 Lactobacillus strains for biofilm formation in tissue culture plates. Results are shown in Fig. 7. The assay revealed a wide range of variation in biofilm formation among the strains with statistically significant differences $(P<0.0001)$. Strain PV036 showed the highest biofilm production, whereas PV031 and PV037 were the lowest biofilm producers.

\section{Adhesion to the intestinal epithelial cell line Caco-2}

The five most promising probiotic candidates were examined for adherence to intestinal epithelial cells. Three strains showed strong adherence levels to human Caco-2 intestinal epithelial cells, similar to the adherence observed with the human intestinal probiotic L. rhamnosus GG and L. johnsonii ATCC 33200 (Fig. 8). Strain PV012 was the most adherent strain in the assay since approximately $7.7 \pm 0.1 \%$ of the added bacteria bound to Caco- 2 cells. PV018 was the least adherent $(1.3 \pm 0.2 \%)$. The adhesion of PV018 and PV017 

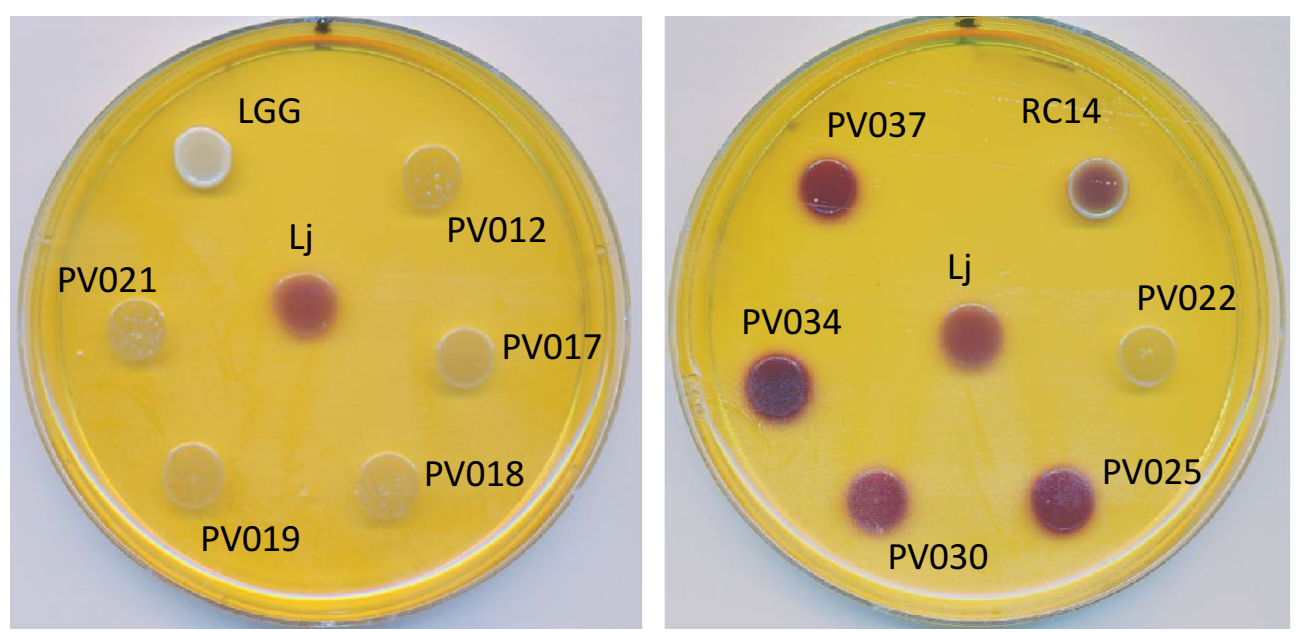

Fig. 6 Hydrogen peroxide production by vole Lactobacillus strains. Representative ABTS agar assay plates indicating peroxide formation in the bacterial colonies are shown. All strains were evaluated following growth on ABTS/peroxidase indicator plates. In this example, colonies of PV025, PV030, PV034, and PV037 as well as the positive controls L. reuteri RC14 and L. johnsonii (Lj) produced $\mathrm{H}_{2} \mathrm{O}_{2}$ (purple color). L. rhamnosus GG (LGG) was included as negative control

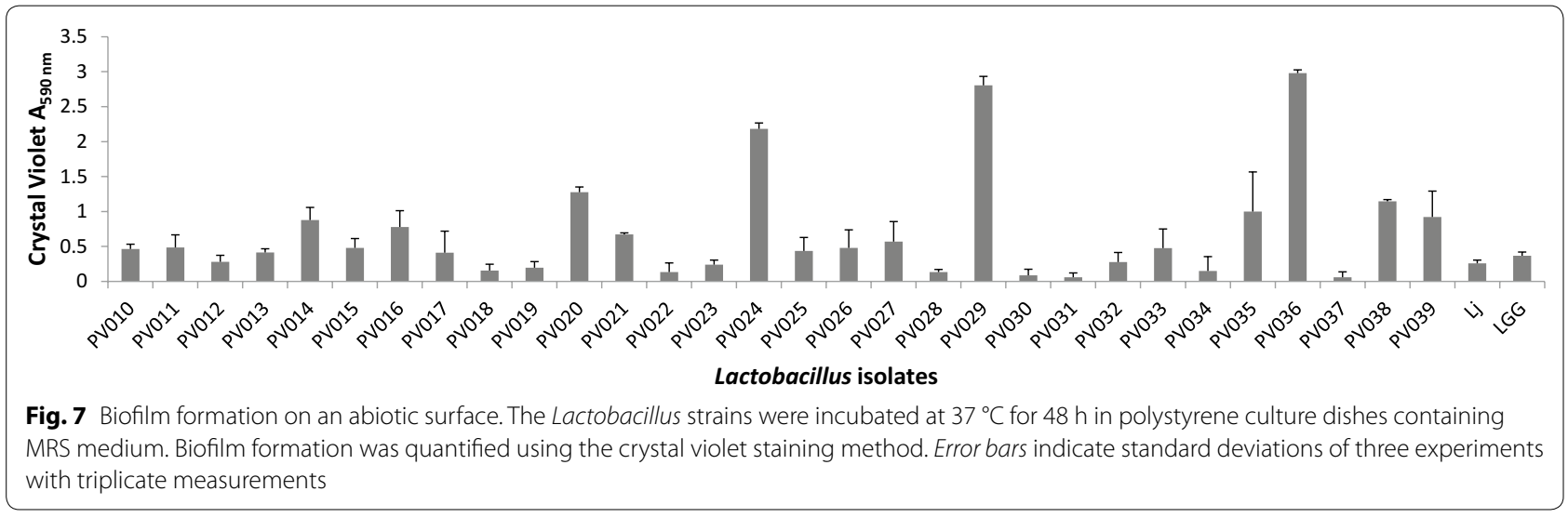

was significantly $(P<0.05)$ lower than the adhesion of PV012, PV019, PV039, ATCC 33200, and LGG.

\section{Antibiotic susceptibility}

The susceptibilities of the five probiotic candidates to eight antibiotics from different antibiotic classes were determined by broth microdilution testing. Relatively low MICs were found with clindamycin, erythromycin, ampicillin, and doxycyclin (see Additional file 2: Table S1). However, the strains and controls (ATCC 33200 and LGG) were highly resistant to the aminoglycoside antibiotic neomycin.

\section{Discussion}

It has become evident that the gut microbiota can influence host physiology, gut brain-communication, brain function and behavior [16]. The emerging concept of intricate involvement of the gut microbiota in the bidirectional communication between the enteric and central nervous systems (gut-brain-axis) raises the possibility of modulation of the integrated neuronal, hormonal and immune pathways by administration of probiotics [13]. In the present study, we isolated and characterized thirty Lactobacillus strains closely related to $L$. johnsonii from prairie voles, animals which have been suggested as a powerful experimental model in which to study the social brain [43]. In light of the in vitro results reported here, we propose the selection of five strains with high probiotic potential for further studies on the potential role of probiotics in modulating neurological disorders that are associated with social withdrawal symptoms. 


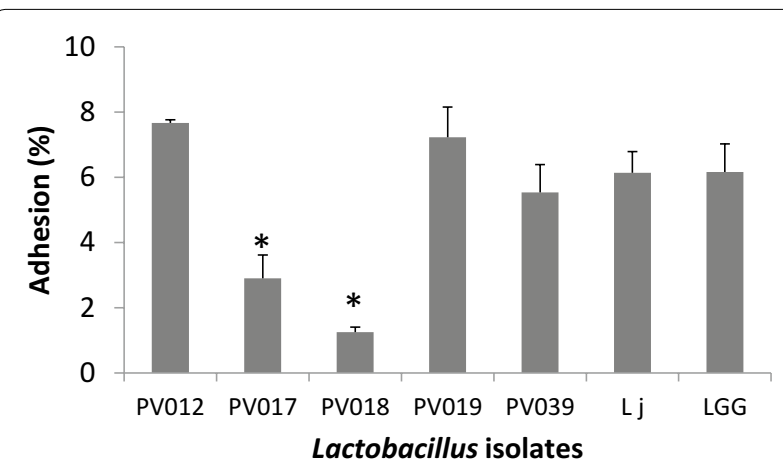

Fig. 8 Adhesion of vole lactobacilli to Caco-2 epithelial cells. Assay results are depicted for the five most promising probiotic candidate strains as well as ATCC 33200 (Lj) and LGG as controls. Adhesion is expressed as the mean percentage of bacteria that bound to Caco-2 cell monolayers relative to the amount of bacteria added. The number of bacterial CFUs added varied between $1.5 \times 10^{8}$ to $3.4 \times 10^{8}$ $\mathrm{CFUs} \mathrm{mL}^{-1}$. Each value represents the mean of triplicate measurements; error bars indicate the standard deviation. ${ }^{*} P<0.05$ (one-way ANOVA)

Lactobacilli are commonly associated with the gastrointestinal tract of animals and humans, as also evidenced by our Lactobacillus abundance results in the vole GI tract (see Fig. 3). Interestingly, these results suggest high numbers of lactobacilli in the stomachs of some animals. Voles, like many herbivorous small mammals, are known to be coprophagic [44]. However, to what extent coprophagy serves to maintain a steady supply of microorganisms, in addition to the well-established nutritional benefits of coprophagy [44], is unknown. Thus, it is unclear whether the relatively high concentrations of lactobacilli in the stomach are the result of recent ingestion of fecal material, or are representative of the normal stomach microbiota in voles.

Probiotic effects of lactobacilli are based on adaptation factors for survival in the host's gastrointestinal tract and probiotic factors for competition with pathogens and further health-promoting interactions with the host [45]. L. johnsonii appears to be the main species of lactobacilli inhabiting the human gastrointestinal tract and some $L$. johnsonii strains have been shown to exert probiotic effects [11, 46, 47]. Factors characteristic of $L$. johnsonii probiotics encompass immunomodulation, the ability to adhere to mammalian cells, and pathogen inhibition through production of antimicrobial substances such as lactic acid and bacteriocins. As an example, $L$. johnsonii NCC533 exerts antimicrobial mechanisms against several pathogens in vitro, including $\mathrm{pH}$ reduction, and lactic acid, bacteriocin and $\mathrm{H}_{2} \mathrm{O}_{2}$ production [48-50]. Here, we report that even though the isolated strains share highly similar $16 \mathrm{~S}$ rRNA gene sequences to the species L. johnsonii, not all Lactobacillus isolates in this study produced the antimicrobial $\mathrm{H}_{2} \mathrm{O}_{2}$ under the test conditions. Nonetheless, the four $\mathrm{H}_{2} \mathrm{O}_{2}$ producers were among the eleven isolates exerting potent antibacterial and even antifungal effects. Although the identities of the inhibitory substances generated by the vole isolates have not been characterized, the broad inhibitory effects against the indicator bacteria and fungi are likely to be due to production of peroxide, organic acids such as lactic acid, bacteriocins, and other antimicrobial substances as reported for many probiotic Lactobacillus strains $[45,51]$. Lactic acid production in concert with a low $\mathrm{pH}$ microenvironment leads to increased cellular toxicity due to diffusion of the undissociated acid into cells and subsequent intracellular acidification which could also promote synergism with other antimicrobial components $[45,52,53]$. Alakomi and coworkers [54] stated that lactic acid, in addition to its antimicrobial property based on lowering of the $\mathrm{pH}$, also functions as a permeabilizer of the outer membrane of gram-negative bacteria, and thus potentiates susceptibility to other antimicrobial molecules.

During passage through the stomach, orally administered probiotics are exposed to high levels of acid stress. The $\mathrm{pH}$ value of gastric juice can vary in the range from 1.5 to 4.5 in a $2 \mathrm{~h}$ period [55]. Thus, probiotic candidates destined to benefit intestinal function must be able to remain viable after several hours in a highly acidic environment. As demonstrated, 17 of the investigated strains revealed acid tolerance after $4 \mathrm{~h}$ incubation under strong acidic conditions and were able to retain cell viability (Fig. 4). The results are similar to previous reports [56, 57] which suggests that the isolated strains have the ability to passage through the stomach without sustaining severe damage.

Resistance to bile and bile acid is another important adaptive factor of probiotics in the intestinal tract. Reports regarding the composition of bile juice from different animals are limited; as a result, most studies used ox gall (bovine bile) as a substitute. The average bile concentration is around $0.3 \%$ and may range up to $2 \%$ during the first hour of digestion [58]. We used bovine bile at concentrations ranging from 0.13 to $8 \%$ to assess bile tolerance of the Lactobacillus strains. Previous reports stated that lactobacilli tolerated on average $0.3 \%[51,55,56]$. After $24 \mathrm{~h}$ incubation, five strains including ATCC 33200 exhibited $\mathrm{IC}_{50}$ values >2\% while the probiotic reference strain $L$. rhamnosus GG showed an $\mathrm{IC}_{50}$ of $1 \%$. Exposure to bile is accompanied by mild acid stress. Therefore, bile resistance is based on hydrolysis of bile (salts) and mechanisms of acid tolerance [45]. Future studies will reveal why some of the isolated strains can withstand such high bile concentrations. 
We also investigated the strains' susceptibility to inorganic mercury, a trait usually not considered in the characterization of probiotics. However, intestinal bacteria, including lactobacilli, play important roles in intestinal homeostasis, and their susceptibility to toxic metals could be of importance in certain gastrointestinal and/ or neurological diseases induced by these metals [59]. Administering probiotics resistant to toxic metals could be an important factor to ameliorate metals-induced neurological disorders, including those associated with social withdrawal symptoms. A goal of this study is the identification of strains with high resistance to mercury chloride in combination with potent probiotic properties, which could potentially be used in future prophylactic or therapeutic interventions in the prairie vole animal model of mercury effects on social behavior [38]. Our in vitro studies revealed that some vole Lactobacillus isolates, in contrast to the lower tolerance of ATCC 33200 , had IC $_{50}$ values as high as $125 \mu \mathrm{mol} / \mathrm{L}$ which is 16,968 times the recommended maximum level of inorganic mercury for human consumption (2 ppb, [60]). A few strains (e.g., PV012, PV037; see Table 3) showed adaptation when the 24-48 $\mathrm{h}$ exposures to $\mathrm{HgCl}_{2}$ were compared. Higher $\mathrm{IC}_{50}$ values at $48 \mathrm{~h}$ could be due to induction of resistance genes/mechanisms, e.g., exerted by detoxifying proteins such as mercuric reductase (merA) or metal transporters. Interestingly, an unpublished draft genome sequence of strain PV012 generated via Ion Torrent PGM sequencing by our laboratory revealed the presence of a potential merA gene (data not shown). This gene might be expressed during extended inorganic mercury exposure to convey detoxification processes. Additionally, binding and sequestration of toxic metals by lactobacilli could be a possible remedial process which could be another probiotic health effect $[37,61,62]$.

Probiotic bacteria can generate biofilms in the intestinal tract, albeit isolated cells and microcolonies appear to be more frequently encountered forms of colonization [45]. Nevertheless, we evaluated the strains for biofilm formation on an abiotic surface (polystyrene) in standard MRS medium without biofilm-promoting stressors (e.g., bile addition or omission of glucose; [63, 64]. Strains PV024, PV029, and PV036 showed the highest biofilm production (Fig. 7), however, these strains exhibited low degrees of antimicrobial activity and tolerance to bile and/or acidic $\mathrm{pH}$ conditions. Thus, under our assay conditions the ability to form biofilms on abiotic surfaces was negatively correlated with probiotic potential.

Adhesion of probiotic bacteria to the intestinal mucosa is considered another important adaptation factor for probiotic activity [45]. Several components of the bacterial cell surface appear to participate in the adherence of the bacterial strains to intestinal epithelial cells.
Adhesion properties are strain characteristics and cannot be generalized to the species and therefore have to be individually tested [45]. In this study, we identified five strains that combined high resistance to acid, bile, and metal toxicity with potent antimicrobial properties and assayed their adhesion to the human intestinal cell line Caco-2. PV012 was the most adhesive strain followed by PV019 and PV039. The observed adhesion percentages were comparable with previous studies [11, 57]. Moreover, the adherence of both PV012 and PV019 was comparable or even better than that of ATCC 33200 and LGG (see Fig. 8). At present little is known whether adhesion of the vole isolates is regulated by inter- or intra-species signaling (quorum sensing) or which cell envelope components are involved in the adhesion process. However, strong adhesion to cells from a non-adapted host suggests a more generalized adhesion mechanism. Future studies will help to elucidate whether adhesion properties are correlated with probiotic effects in vivo.

The antibiotic susceptibility profiles of the prairie vole Lactobacillus strains (see Additional file 2: Table S1) could be of interest for future genetic manipulations of these bacteria and also for studies on the effects of antibiotics on the vole gastrointestinal microbiome.

Most importantly, future studies will investigate whether the isolated Lactobacillus strains are capable of influencing brain function and thereby altering behavior. In this context, probiotic effects on the highly developed social behavior of these animals will be of particular interest.

\section{Conclusions}

Through the combined use of enrichment media, $16 \mathrm{~S}$ rRNA gene sequencing and molecular strain typing, we isolated and differentiated thirty Lactobacillus strains from the prairie vole intestine. The described characterization of a set of adaptive and probiotic factors led to the selection of five vole Lactobacillus strains: PV012, PV017, PV018, PV019, and PV039. The selected strains showed evidence of potent antibacterial and antifungal properties, strong adherence to intestinal epithelial cells as well as resistance to bile and low $\mathrm{pH}$. Moreover, they could potentially be employed in intestinal detoxification of inorganic mercury. Thus, the selected strains meet important prerequisites to study probiotic health effects in the prairie vole social behavior model.

\section{Methods}

\section{Strains and culture conditions}

Bacteria and fungi used in this study are shown in Table 1. Bacterial cultures were routinely grown in Difco Lactobacilli MRS broth (de Mann, Rogosa and Sharpe medium for lactobacilli; BD Diagnostics, Franklin Lakes, 
NJ, USA) or Luria-Bertani broth (LB Miller, Fisher Scientific, Pittsburgh, PA, USA; for E. coli, Staphylococcus aureus, and Pseudomonas aeruginosa) at $37{ }^{\circ} \mathrm{C}$. YPD medium (Fisher Scientific; $10 \mathrm{~g} / \mathrm{L}$ yeast extract, $20 \mathrm{~g} / \mathrm{L}$ tryptone, $20 \mathrm{~g} / \mathrm{L}$ dextrose) was used for growing Candida albicans. Solid media were generated by adding $15 \mathrm{~g} / \mathrm{L}$ (bacteria) or $20 \mathrm{~g} / \mathrm{L}$ (fungi) agar to the respective media. Stock cultures were maintained at $-80{ }^{\circ} \mathrm{C}$ with $15 \% \mathrm{v} / \mathrm{v}$ glycerol as cryopreservative.

\section{Animal care and handling}

The voles used in this study were sexually-naïve adult ( $>60$ days of age) male and female prairie voles (Microtus ochrogaster) from a laboratory breeding-colony descended from an Illinois population and were of the F4 and F5 generations relative to most recent out-crossing with wild stock. Voles are housed at $21{ }^{\circ} \mathrm{C}$ with a $14: 10$ light:dark cycle. Breeding pairs are housed in plastic cages $(20 \times 25 \times 45 \mathrm{~cm})$ containing corncob bedding with hay as nesting material. Ad libitum food (Purina rabbit chow supplemented with black-oil sunflower seeds) and water are available. After weaning at 21 days of age, offspring are housed in same-sex pairs in plastic cages $(10 \times 17 \times 28 \mathrm{~cm})$ until used in experiments. Except for the breeding pairs, sexes are maintained in separate rooms until used in experiments. The general experimental manipulations and animal handling procedures were approved by the Oklahoma State University Center for Health Sciences Institutional Animal Care and Use Committee.

\section{Bacterial strain isolation from the prairie vole $\mathrm{Gl}$ tract}

The bacterial strains isolated and characterized in this study are shown in Table 1. Two animals from each sex were euthanized and duplicate intestinal specimens were collected from the cecum, small intestine and colon. Following suspension of intestinal content in $0.5 \mathrm{~mL}$ sterile water, a dilution series $\left(10^{0}-10^{-5}\right)$ was prepared for each sample and $100 \mu \mathrm{L}$ of each dilution were cultured immediately on MRS agar plates. Samples from different animals or sites were kept separate. Enrichment for lactobacilli was achieved under anaerobic growth conditions at $37{ }^{\circ} \mathrm{C}$ for $48 \mathrm{~h}$ using a GasPak ${ }^{\mathrm{TM}} 100$ container and EZ Anaerobe Pouch system (BD Diagnostics). Subsequently, bacterial colonies were randomly selected (up to 10 colonies per plate) and sub-cultured at least twice for purification. Only isolates with good and uniform growth on MRS agar were considered for further study. Following repeated purification, a distinct colony from selected isolates was used as inoculum for liquid MRS cultures. After 24-48 h of growth, frozen stock cultures with $15 \%(\mathrm{v} / \mathrm{v})$ glycerol as cryopreservative were prepared from these cultures. Working cultures were routinely propagated from the stocks aerobically or anaerobically.

\section{Lactobacillus DNA extraction, PCR and 16S rRNA-based identification}

DNA extractions were performed from each of the thirty isolates. Bacterial DNA was isolated from $10 \mathrm{ml}$ MRS broth culture grown overnight using a ZR Fungal/ Bacterial DNA MiniPrep ${ }^{\mathrm{TM}}$ kit (Zymo Research, Irvine, CA, USA) following the manufacturer's instructions. In brief, bacterial cells were harvested by centrifugation at $4500 \times g$ for $10 \mathrm{~min}$ at $4{ }^{\circ} \mathrm{C}$ and re-suspended in $750 \mu \mathrm{L}$ of lysis buffer and added to ZR Bashing Bead Lysis tubes. A Mini-Beadbeater-96 (Biospec Products, Bartlesville, OK, USA) was employed for cell disruption. The resulting crude bacterial cell homogenates were processed for genomic DNA isolation according to the kit's instructions. DNA concentrations were determined using a BioTek Synergy 2 Multimode Microplate Reader (BioTek Instruments, Inc. Winooski, Vermont).

The universal primers $8 \mathrm{~F}$ and 1491R (see Table 2) were used to generate PCR amplicons of the bacterial $16 \mathrm{~S}$ rRNA genes [65]. PCRs were carried out in a PTC-200 DNA Engine thermocycler (Bio Rad, Hercules, CA, USA) in $50 \mu \mathrm{L}$ reactions employing AmpliTaq Gold 360 Master Mix (25 $\mu \mathrm{L}$, Life Technologies, Carlsbad, CA, USA), $0.2 \mu \mathrm{M}$ of $8 \mathrm{~F} / 1491 \mathrm{R}$ primer mix, and $1-2 \mu \mathrm{L}$ bacterial DNA solution (100 ng) following the manufacturer's guidelines. Amplification parameters consisted of an initial denaturation step at $95^{\circ} \mathrm{C}$ for $10 \mathrm{~min}$ followed by 30 cycles of $15 \mathrm{~s}$ at $95{ }^{\circ} \mathrm{C}, 30 \mathrm{~s}$ at $55^{\circ} \mathrm{C}$, and $90 \mathrm{~s}$ at $72{ }^{\circ} \mathrm{C}$. A final extension step at $72{ }^{\circ} \mathrm{C}$ for 10 min completed the reactions. Aliquots of the PCRs were evaluated by gel electrophoresis on $1 \%$ agarose gels. Successful PCRs were purified and concentrated using the ZR DNA Clean and Concentrator 25 kit (Zymo Research) according to the manufacturer's instructions.

Sanger sequencing of the isolates' $16 \mathrm{~S}$ rRNA gene amplicons was performed for species identification. PCR amplicons from twelve isolates were cloned in the pCR4TOPO vector (TOPO TA Cloning Kit, Invitrogen, Carlsbad, CA, USA) for sequencing, whereas the remaining eighteen PCR amplicons were directly sequenced. The latter approach yielded results faster, while still providing the sequence information necessary for classification of the strains. Recombinant plasmids were transformed into E. coli Novablue Singles ${ }^{\mathrm{TM}}$ competent cells (EMD Millipore, Billerica, MA, USA) by electroporation using an ECM 399 electroporation system (BTX Harvard Apparatus, Holliston, MA, USA). Plasmids from successful transformations were isolated with the Zyppy Plasmid Midiprep kit (Zymo Research) following the manufacturer's instructions and then sequenced. Amplicons/plasmid inserts were sequenced from both directions at the OSU Stillwater Recombinant DNA/Protein Core Facility. For classification of the isolates, the assembled sequences 
were compared to published 16S rDNA sequences in the NCBI GeneBank and Greengenes databases (http://www. greengenes.lbl.gov/blast; [66]) using the BLAST tool.

\section{Determination of the relative abundance of lactobacilli in the prairie vole $\mathrm{Gl}$ tract}

The relative abundance of Lactobacillus 16S rRNA gene copies in various regions of the prairie vole gastrointestinal tract (stomach, proximal and distal small intestine, cecum, and colon) was determined by exonuclease-based quantitative real-time PCR (qPCR). For this purpose, DNA was isolated from gastrointestinal contents of five female and seven male animals (one sample per site) using the ZR Fecal DNA MiniPrep kit (Zymo Research) according to the manufacturer's directions. A groupspecific assay to detect lactobacilli was designed employing the primer pair TaqLacF-TaqLacR in conjunction with the hydrolysis probe GKLPV16STaq (Table 2). For normalization across samples, qPCR assays with broadrange primers (GK1053F-1391R) and the hydrolysis probe GKUNI16STaqCCC were used. Quantitative PCR reactions were run on Applied Biosystems StepOne ${ }^{\mathrm{TM}}$ or 7500 real-time PCR systems using the TaqMan Universal Master MixII with UNG reagents (Life Technologies) and the following reaction parameters: UNG incubation $2 \mathrm{~min}$ at $50{ }^{\circ} \mathrm{C}$, polymerase activation $10 \mathrm{~min}$ at $95{ }^{\circ} \mathrm{C}$, 40 cycles of denaturation $\left(30 \mathrm{~s}\right.$ at $\left.95^{\circ} \mathrm{C}\right)$, annealing $(30 \mathrm{~s}$ at $52{ }^{\circ} \mathrm{C}$ ), and extension $\left(90 \mathrm{~s}\right.$ at $\left.65^{\circ} \mathrm{C}\right)$. Ribosomal RNA copy numbers were determined by comparison of quantification cycle values (Cq) of sample assays with standard curves generated with PLBB4c, a plasmid containing a Lactobacillus 8F-1491R 16S rRNA gene fragment that provided a quantified template for both targets. Assays were replicated at least in duplicate. Relative abundances of Lactobacillus 16S rRNA gene copies in each sample were calculated as percentages of the respective broadrange $P C R$ values.

Random amplified polymorphic DNA (RAPD) fingerprinting Randomly amplified polymorphic DNA analysis was used to genetically differentiate the isolated Lactobacillus strains. For RAPD fingerprinting, the same bacterial DNA extracts were used as for cloning and sequencing so that the results could be directly matched. RAPD analysis was adapted from a previously described procedure [39]. The oligonucleotide primer RAPD 272 (see Table 2) was used throughout the study. PCRs were run on a PTC-200 DNA Engine thermocycler (Bio Rad) in $25 \mu \mathrm{L}$ reactions employing AmpliTaqGold 360 Master Mix $(12.5 \mu \mathrm{L}$, Life Technologies, Carlsbad, CA, USA), $10 \mu \mathrm{mol} / \mathrm{L}$ primer and $100 \mathrm{ng}$ template DNA. PCR cycles were performed as follows: (1) 4 cycles of $94{ }^{\circ} \mathrm{C}$ for $5 \mathrm{~min}, 36{ }^{\circ} \mathrm{C}$ for $5 \mathrm{~min}$ (70 s ramp time), and $72{ }^{\circ} \mathrm{C}$ for $5 \mathrm{~min}$ (70 s ramp time),
(2) 30 cycles of $94{ }^{\circ} \mathrm{C}$ for $1 \mathrm{~min}\left(55 \mathrm{~s}\right.$ to heat from $\left.72{ }^{\circ} \mathrm{C}\right)$, $36{ }^{\circ} \mathrm{C}$ for $1 \mathrm{~min}$. (60 s ramp time), $72{ }^{\circ} \mathrm{C}$ for $2 \min (70 \mathrm{~s}$ ramp time); and (3) a final extension of $72{ }^{\circ} \mathrm{C}$ for $6 \mathrm{~min}$ followed by a hold at $4{ }^{\circ} \mathrm{C}$. All Lactobacillus strains were processed in duplicate to ensure RAPD typing was reproducible and reliable. The probiotic strains $L$. johnsonii ATCC 33200 and L. rhamnosus GG were used as references. PCR amplicons were separated by gel electrophoresis using $1.5 \%$ high resolution agarose gels in $1 \times$ Tris-Acetate-EDTA buffer with a 100 bp DNA ladder (New England Biolabs, Ipswich, MA, USA) as size marker. Gels were stained with SYBR Safe DNA gel stain (Life Technologies) and scanned with a Typhoon 9410 Variable Mode Imager (GE Healthcare Biosciences, Pittsburgh, PA, USA). The resulting fingerprint bands were analyzed with Image Quant TL software (GE Healthcare) and PCR fragments patterns for each strain were determined. These amplicon patterns were used for cluster analyses to compare RAPD results of the Lactobacillus strains using "DendroUPGMA" (http://genomes.urv.cat/ UPGMA/; [67]).

\section{Acid tolerance test}

Freshly grown Lactobacillus cultures were pelleted at $4500 \times g$ for $10 \mathrm{~min}$ at $4{ }^{\circ} \mathrm{C}$, washed twice and re-suspended in sterile phosphate-buffered saline (PBS, pH 7.2). Each pellet was diluted to $\mathrm{OD}_{600 \mathrm{~nm}}=0.05$ in PBS at $\mathrm{pH} 1-5,7$ (adjusted with $1.0 \mathrm{~N} \mathrm{HCl}$ ) and incubated at $37^{\circ} \mathrm{C}$ for 1,2 , and $4 \mathrm{~h}$. Subsequently, $20 \mu \mathrm{L}$ of the bacteria were inoculated into Cellstar 96-well tissue culture plates (Greiner Bio-One, Monroe, NC, USA) containing $180 \mu \mathrm{L}$ of MRS broth and incubated at $37^{\circ} \mathrm{C}$ for $24 \mathrm{~h}$. Growth was determined by $\mathrm{OD}_{600 \mathrm{~nm}}$ readings on a microplate reader.

\section{Bile and bile acid tolerance test}

The method described by Ehrmann and coworkers [56] was used for testing tolerance to bovine bile (B3833, Sigma-Aldrich) and taurocholate (T4009, SigmaAldrich). Following overnight cultures in MRS, the bacteria were inoculated to a starting $\mathrm{OD}_{600 \mathrm{~nm}}=0.05$ in 96-well tissue culture plates containing MRS with dilution series of bovine bile $(0.13,0.25,0.5,1,2,4$, and $8 \% \mathrm{w} / \mathrm{v})$ or taurocholate $(0.2,0.4,0.9,1.8,3.5,7.0$, and $14 \mathrm{mmol} / \mathrm{L}$ ). MRS broth without addition of inhibitors was used as control. After incubation for $24 \mathrm{~h}$, growth was determined by $\mathrm{OD}_{600 \mathrm{~nm}}$ readings. Each assay was carried out in duplicate wells and repeated three times.

\section{Antimicrobial effects towards bacteria and fungi}

The antimicrobial activity in Lactobacillus culture supernatants was tested as previously described by Lee and coworkers [68]. Briefly, the vole Lactobacillus strains and 
the two reference strains (ATCC 33200 and LGG) were cultured overnight in 6-well tissue culture plates (Cellstar, Greiner Bio-One). Cell-free supernatants were harvested by centrifugation for $5 \mathrm{~min}$ at $4000 \times g$, sterilized with $0.2 \mu \mathrm{m}$ polyethersulfone membrane syringe filters, and $100,50,25,12.5,6.25,3.12$, and $1.6 \mu \mathrm{L}$ of the supernatants were pipetted into Cellstar 96-well tissue culture plates. The volume in each well was adjusted to $100 \mu \mathrm{L}$ with MRS broth. As indicator microorganisms, the pathogens $P$. aeruginosa, S. aureus, C. albicans, and the non-pathogenic K-12 E. coli strain NovaBlue Singles (see Table 1) were added in $100 \mu \mathrm{L}$ fresh medium (LB for $E$. coli and $P$. aeruginosa, MRS for C. albicans and S. aureus; all adjusted $\mathrm{OD}_{600 \mathrm{~nm}}=0.01$ ) into the wells containing Lactobacillus supernatants and incubated for $24 \mathrm{~h}$ at $37{ }^{\circ} \mathrm{C}$. Pure cultures of each indicator microorganism were included as controls. Growth of the indicators was assessed by optical density readings at $600 \mathrm{~nm}$ in a Biotek Synergy 2 microplate reader. The assay was carried out in duplicate wells and repeated three times with all microbial cultures prepared fresh from frozen stocks.

\section{Analysis of $\mathrm{H}_{2} \mathrm{O}_{2}$ production}

The ability of the isolates to produce hydrogen peroxide was determined qualitatively using the $2,2^{\prime}$-azinobis(3-ethylbenzoline-6-sulfonic acid) diammonium salt (ABTS)-MRS agar method [69]. Thirty mg of ABTS (Sigma, St. Louis, MO, USA) and $2 \mathrm{mg}$ of horseradish peroxidase (Sigma, St. Louis, MO, USA) were dissolved in $10 \mathrm{~mL}$ distilled water and filter-sterilized. This ABTS/ peroxidase solution was added to $90 \mathrm{~mL}$ of MRS agar that had been cooled to $50{ }^{\circ} \mathrm{C}$ following autoclaving. Twentyfive $\mathrm{mL}$ of the solution were poured into petri dishes and left to solidify. Four $\mu \mathrm{L}$ of freshly grown Lactobacillus suspensions adjusted to $\mathrm{OD}_{600 \mathrm{~nm}}=1$ were spotted on the agar plates and incubated for $24 \mathrm{~h}$ under anaerobic conditions. Subsequently, culture plates were exposed to ambient air for up to $24 \mathrm{~h}$ for pigment formation. Production of hydrogen peroxide was visualized by light to dark purple colonies. Each assay was performed in duplicate plates and repeated three times. Probiotic strains $L$. reuteri $\mathrm{RC}-14$ and L. rhamnosus GG were included as positive and negative controls, respectively.

\section{Mercuric chloride resistance assay}

For determining the strains' resistance to $\mathrm{HgCl}_{2}(215465$, Sigma-Aldrich), the Lactobacillus strains were grown aerobically overnight in MRS broth. The assay was performed in 96-well plates with $100 \mu \mathrm{L}$ inocula in MRS $\left(\mathrm{OD}_{600 \mathrm{~nm}}=0.05\right)$ prepared from the overnight cultures and additional $100 \mu \mathrm{L}$ of MRS broth containing $\mathrm{HgCl}_{2}$ dilutions to achieve end concentrations of $0.5,0.25$, $0.125,0.0625,0.031,0.015$, and $0.008 \mathrm{mmol} / \mathrm{L}$. Wells containing MRS broth without $\mathrm{HgCl}_{2}$ were included as a control. Growth was monitored at 24 and $48 \mathrm{~h}$ using a BioTek Synergy 2 microplate reader for $\mathrm{OD}_{600 \mathrm{~nm}}$ determinations. All tests were performed in triplicate wells and the experiment was repeated thrice.

\section{Biofilm formation}

The ability of the Lactobacillus strains to form biofilms on plastic surfaces was quantified using the crystal violet staining method [70]. The strains were grown in MRS medium in a 6-well plate under aerobic conditions for $48 \mathrm{~h}$. Subsequently, the culture medium was aspirated and adherent cells were washed twice with sterile PBS. Three $\mathrm{mL}$ of $0.02 \%$ crystal violet $(\mathrm{w} / \mathrm{v})$ was added into each well to stain the surface attached bacteria and incubated for $20 \mathrm{~min}$. Excess dye was rinsed off by washing the cells 5 times with distilled water. Two $\mathrm{mL}$ ethanol (95\%) was added to each well to redissolve the crystal violet dye from the biofilms. Following alcoholic elution, $200 \mu \mathrm{L}$ aliquots of the eluate were transferred to a microplate and the absorbance was read at $590 \mathrm{~nm}$ in a Synergy 2 Multimode Microplate Reader. All tests were carried out in triplicate wells and repeated three times.

\section{Caco- 2 cell adhesion assay}

The Caco-2 cell line (HTB-37) was purchased from the American Type Culture Collection (ATCC, Rockville, MD, USA). The cells were cultured in Dulbecco's modified Eagle's minimal essential medium (DMEM; Life Technologies) supplemented with $10 \%(\mathrm{v} / \mathrm{v})$ heat-inactivated $\left(30 \mathrm{~min}, 56^{\circ} \mathrm{C}\right.$ ) fetal bovine serum (Life Technologies), $100 \mathrm{U} / \mathrm{mL}$ penicillin, and $100 \mathrm{mg} / \mathrm{mL}$ streptomycin (Life Technologies) at $37{ }^{\circ} \mathrm{C}, 5 \% \mathrm{CO}_{2}$ in a Heracell $150 \mathrm{i}$ incubator (Thermo Scientific, Rockford, IL, USA). For adhesion assays, Caco-2 monolayers were prepared in 24-well standard tissue culture plates (Cellstar, Greiner Bio-One). The Caco-2 cells were seeded at a concentration of $1.0 \times 10^{4}$ cells per well to obtain confluence and maintained for 20 days prior to the adhesion assays. The cell culture medium was replaced every other day. The number of cells per well was determined by trypsinization of the monolayer and counting using a hemocytometer. In addition, cell number and viability of the monolayer was confirmed using the PrestoBlue Cell Viability Reagent kit according to manufacturer's instructions (Life Technologies).The adherence of Lactobacillus strains to Caco-2 cells was determined by the method of Fernandez et al. [71] with some modifications. Briefly, the Caco-2 monolayer was washed twice with phosphatebuffered saline (PBS) pH 7.4 (Sigma). PBS was also used to wash and adjust the lactobacilli to desired cell densities. Dilutions according to $\mathrm{OD}_{600 \mathrm{~nm}}$ readings were used for approximation of cell densities. Viable bacterial cell 
numbers introduced in the adhesion assays were determined by CFU counting on MRS agar. Bacteria from an overnight culture were washed in PBS. For each adhesion assay, $500 \mu \mathrm{L}$ of Lactobacillus suspension ranging from $1.5 \times 10^{8}$ to $4.9 \times 10^{8}$ cells per ml were added to the wells containing Caco-2 monolayers and incubated at $37{ }^{\circ} \mathrm{C}$ in $5 \% \mathrm{CO}_{2}$ atmosphere. After $90 \mathrm{~min}$ of incubation, the Caco-2 monolayers were washed three times with PBS to release non-adherent bacteria. In order to enumerate the attached viable bacteria, the mammalian cells were lysed in sterile water by repeated up and down pipetting for $10 \mathrm{~min}$. Appropriate dilutions of the mixtures of lysed Caco-2 cells and bacteria were plated on MRS agar plates and incubated at $37^{\circ} \mathrm{C}$. The CFU count was determined after $48 \mathrm{~h}$ incubation. Data were expressed as the percent adhesion rate, i.e., the ratio between the number of adherent bacteria and the number of bacteria added to the cell monolayer. Each adhesion assay was performed in duplicate wells with cells from three successive passages (P5, P8, and P14). ATCC 33200 and LGG were included as reference strains.

\section{Antibiotic susceptibility testing}

The antibiotic susceptibilities of selected Lactobacillus strains (five prairie vole isolates and two controls) were determined using a broth microdilution assay as described previously [72]. The microplate assay was adapted to MRS medium in order to support vigorous growth of lactobacilli. Eight antimicrobial drugs representing different antibiotic classes were tested: ampicillin, chloramphenicol, neomycin (A9518, C0378, N6386; Sigma-Aldrich), doxycycline, ciprofloxacin (BP2653, 449620050; Thermo Fisher Scientific), erythromycin, cephalexin monohydrate, and clindamycin $\mathrm{HCl}$ (E57000, C59000, C41050, Research Products International Corp.; Mount Prospect, IL, USA). Antibiotic stock solutions were prepared according to the manufacturers' recommendations and diluted to final assay concentrations of $64-0.125 \mathrm{mg} / \mathrm{L}$ or $128-0.25 \mathrm{mg} / \mathrm{L}$ (only neomycin and cephalexin) in assay volumes of $200 \mu \mathrm{l}$ per microplate well [72]. Lactobacillus inocula were adjusted to $\mathrm{OD}_{600 \mathrm{~nm}}=0.001$ and plates were read after $18 \mathrm{~h}$ of incubation. The minimum inhibitory concentration (MIC) was defined as the lowest concentration of antibiotic giving a complete inhibition of visible bacterial growth in comparison to control wells [72]. All tests were performed twice with duplicate wells.

\section{Statistical analysis}

All quantitative data are the average of three independent experiments \pm standard deviations (mean \pm SD). Statistical significance of the results was evaluated by one-way or two-way analysis of variance (ANOVA) using the IBM SPSS Statistics package (version 19) and PRISM (version
5; GraphPad Software, La Jolla, CA, USA). A $P<0.05$ was considered statistically significant.

\section{Additional files}

Additional file 1: Figure S1. Phylogenetic tree of 165 rRNA gene sequences. The $16 \mathrm{~S}$ rRNA gene sequences of the prairie vole isolates were obtained by Sanger sequencing of $16 \mathrm{~S}$ amplicons (primers 8F-1491R) and next-generation genome sequencing for isolates PV012, PV021, and PV034 (NGS sequence designations). Multiple NGS contigs for these strains most likely represent distinct rDNA operons. The sequences were aligned to Lactobacillus johnsonii ATCC 33200 (Lj; NR_025273) and L. rhamnosus GG (LGG; NR_102778) 16S rDNAs. Following manual trimming of the multiple sequence alignment ends, the sequences were used to generate the depicted phylogenetic tree using the CLC Genomics Workbench Maximum Likelihood Phylogeny algorithm (UPGMA starting tree, General Time Reversible substitution model).

Additional file 2: Table S1. Antibiotic susceptibilities of the selected prairie vole Lactobacillus strains.

\section{Authors' contributions}

SA: contributions to concepts, design, performed experiments, input to analysis and interpretation of data, contribution in drafting and revising the manuscript. KA performed the Lactobacillus abundance analysis. SB provided draft genome sequences for strain PV012, PV021, and PV034. JTC provided animals and managed the prairie vole colony for the entire project. GAK: project $\mathrm{Pl}$, was involved in strain isolation, sequencing, analysis and interpretation of data, writing, editing and revising of the manuscript. All authors read and approved the final manuscript.

\section{Author details}

${ }^{1}$ Department of Biochemistry and Microbiology, Oklahoma State University Center for Health Sciences, 1111 West 17th Street, Tulsa, OK 74107, USA. ${ }^{2}$ Department of Pharmacology and Physiology, Oklahoma State University Center for Health Sciences, Tulsa, USA.

\section{Acknowledgements}

This research was supported by the Oklahoma State University Center for Health Sciences (OSU-CHS). Additional funding to GAK was provided by the Health Research award project number HR13-013 from the Oklahoma Center for the Advancement of Science and Technology. The StepOne ${ }^{\mathrm{TM}}$ Real-Time PCR system used in this study was supported by Cancer Sucks Inc., Bixby, OK, USA. The authors are thankful to Dr. Robert Allen, OSU-CHS Department of Forensic Sciences, for providing access to the ABI 7500 Real-Time PCR system and to Dr. Gregor Reid, R\&D Centre for Probiotics, Lawson Health Research Institute, University of Western Ontario, London, ON, Canada, for providing L. reuteri $\mathrm{RC}-14$.

\section{Competing interests}

The authors declare that they have no competing interests.

Received: 26 October 2015 Accepted: 15 December 2015

Published online: 30 December 2015

\section{References}

1. Hill C, Guarner F, Reid G, Gibson GR, Merenstein DJ, Pot B, et al. Expert consensus document. The International Scientific Association for probiotics and prebiotics consensus statement on the scope and appropriate use of the term probiotic. Nat Rev Gastroenterol Hepatol. 2014;11(8):50614. doi:10.1038/nrgastro.2014.66

2. Metchnikoff E. Essais optimistes. Paris: A. Maloine; 1907.

3. Ahrne S, Nobaek S, Jeppsson B, Adlerberth I, Wold AE, Molin G. The normal Lactobacillus flora of healthy human rectal and oral mucosa. J Appl Microbiol. 1998;85(1):88-94. 
4. Reid G, Kim SO, Köhler GA. Selecting, testing and understanding probiotic microorganisms. FEMS Immunol Med Microbiol. 2006;46(2):149-57.

5. Antonio MA, Hawes SE, Hillier SL. The identification of vaginal Lactobacillus species and the demographic and microbiologic characteristics of women colonized by these species. J Infect Dis. 1999;180(6):1950-6. doi:10.1086/315109.

6. Gustafsson RJ, Ahrne S, Jeppsson B, Benoni C, Olsson C, Stjernquist M, et al. The Lactobacillus flora in vagina and rectum of fertile and postmenopausal healthy Swedish women. BMC Womens Health. 2011;11(1):17. doi:10.1186/1472-6874-11-17.

7. Hummelen R, Macklaim JM, Bisanz JE, Hammond JA, McMillan A, Vongsa $R$, et al. Vaginal microbiome and epithelial gene array in post-menopausal women with moderate to severe dryness. PLoS One. 2011;6(11):e26602. doi:10.1371/journal.pone.0026602.

8. Salvetti E, Torriani S, Felis G. The genus Lactobacillus: a taxonomic update. Probiotics Antimicro Prot. 2012;4(4):217-26. doi:10.1007/ s12602-012-9117-8.

9. Mercenier A, Pavan S, Pot B. Probiotics as biotherapeutic agents: present knowledge and future prospects. Curr Pharm Des. 2003;9(2):175-91.

10. Pridmore RD, Berger B, Desiere F, Vilanova D, Barretto C, Pittet AC, et al. The genome sequence of the probiotic intestinal bacterium Lactobacillus johnsonii NCC 533. Proc Natl Acad Sci USA. 2004;101(8):2512-7.

11. Yamano $T$, lino $H$, Takada M, Blum S, Rochat F, Fukushima Y. Improvement of the human intestinal flora by ingestion of the probiotic strain Lactobacillus johnsonii La1. Br J Nutr. 2006;95(2):303-12.

12. Bercik P, Denou E, Collins J, Jackson W, Lu J, Jury J et al. The intestinal microbiota affect central levels of brain-derived neurotropic factor and behavior in mice. Gastroenterology. 2011;141(2):599-609, e1-3. doi:10.1053/j.gastro.2011.04.052

13. Bravo JA, Forsythe P, Chew MV, Escaravage E, Savignac HM, Dinan TG, et al. Ingestion of Lactobacillus strain regulates emotional behavior and central GABA receptor expression in a mouse via the vagus nerve. Proc Natl Acad Sci USA. 2011;108(38):16050-5. doi:10.1073/pnas.1102999108.

14. Kamiya T, Wang L, Forsythe P, Goettsche G, Mao Y, Wang Y, et al. Inhibitory effects of Lactobacillus reuteri on visceral pain induced by colorectal distension in Sprague-Dawley rats. Gut. 2006;55(2):191-6. doi:10.1136/ gut.2005.070987.

15. Bravo JA, Julio-Pieper M, Forsythe P, Kunze W, Dinan TG, Bienenstock J, et al. Communication between gastrointestinal bacteria and the nervous system. Curr Opin Pharmacol. 2012;12(6):667-72. doi:10.1016/j. coph.2012.09.010.

16. Cryan JF, Dinan TG. Mind-altering microorganisms: the impact of the gut microbiota on brain and behaviour. Nat Rev Neurosci. 2012;13(10):70112. doi:10.1038/nrn3346.

17. Aragona BJ, Wang Z. The prairie vole (Microtus ochrogaster): an animal model for behavioral neuroendocrine research on pair bonding. ILAR J. 2004;45(1):35-45

18. Carter CS, DeVries AC, Getz LL. Physiological substrates of mammalian monogamy: the prairie vole model. Neurosci Biobehav Rev. 1995;19(2):303-14. doi:10.1016/0149-7634(94)00070-H.

19. Insel TR. A neurobiological basis of social attachment. Am J Psychiatry. 1997;154(6):726-35

20. Young LJ, Pitkow LJ, Ferguson JN. Neuropeptides and social behavior: animal models relevant to autism. Mol Psychiatry. 2002;7(suppl 2):S38-9. doi:10.1038/sj.mp.4001175.

21. Getz L, Carter CS, Gavish L. The mating system of the prairie vole, Microtus ochrogaster: field and laboratory evidence for pair-bonding. Behav Ecol Sociobiol. 1981;8(3):189-94. doi:10.1007/BF00299829.

22. DeVries AC. Interaction among social environment, the hypothalamicpituitary-adrenal axis, and behavior. Horm Behav. 2002;41(4):405-13. doi:10.1006/hbeh.2002.1780.

23. DeVries AC, DeVries MB, Taymans SE, Carter CS. The effects of stress on social preferences are sexually dimorphic in prairie voles. Proc Natl Acad Sci USA. 1996;93(21):11980-4.

24. DeVries AC, Glasper ER, Detillion CE. Social modulation of stress responses. Physiol Behav. 2003;79(3):399-407.

25. DeVries AC, Taymans SE, Carter CS. Social modulation of corticosteroid responses in male prairie voles. Ann NY Acad Sci. 1997;807:494-7.

26. Klein SL, Hairston JE, Devries AC, Nelson RJ. Social environment and steroid hormones affect species and sex differences in immune function among voles. Horm Behav. 1997;32(1):30-9. doi:10.1006/hbeh.1997.1402.
27. Carter CS, Getz LL. Monogamy and the prairie vole. Sci Am. 1993;268(6):100-6.

28. Grippo AJ, Lamb DG, Carter CS, Porges SW. Cardiac regulation in the socially monogamous prairie vole. Physiol Behav. 2007;90(2-3):386-93. doi:10.1016/j.physbeh.2006.09.037.

29. Curtis JT, Wang Z. The neurochemistry of pair bonding. Curr Dir Psychol Sci. 2003;12(2):49-53. doi:10.1111/1467-8721.01224.

30. Kenkel WM, Yee JR, Porges SW, Ferris CF, Carter CS. Cardioacceleration in alloparents in response to stimuli from prairie vole pups: the significance of thermoregulation. Behav Brain Res. 2015;286:71-9. doi:10.1016/j. bbr.2015.02.033.

31. Lyons SA, Getz LL. Reproductive activation of virgin female prairie voles (Microtus ochrogaster) by paired and unpaired males. Behav Process. 1993;29(3):191-9. doi:10.1016/0376-6357(93)90123-9.

32. Taylor SA, Salo AL, Dewsbury DA. Estrus induction in four species of voles (Microtus). J Comp Psychol. 1992;106(4):366-73.

33. Pierides M, El-Nezami H, Peltonen K, Salminen S, Ahokas J. Ability of dairy strains of lactic acid bacteria to bind aflatoxin $\mathrm{M} 1$ in a food model. J Food Prot. 2000;63(5):645-50.

34. Meriluoto J, Gueimonde M, Haskard CA, Spoof L, Sjovall O, Salminen S. Removal of the cyanobacterial toxin microcystin-LR by human probiotics. Toxicon. 2005:46(1):111-4. doi:10.1016/j.toxicon.2005.03.013.

35. Bhakta JN, Ohnishi K, Munekage Y, Iwasaki K, Wei MQ. Characterization of lactic acid bacteria-based probiotics as potential heavy metal sorbents. J Appl Microbiol. 2012;112(6):1193-206. doi:10.1111/j.1365-2672.2012.05284.x.

36. Halttunen T, Salminen S, Tahvonen R. Rapid removal of lead and cadmium from water by specific lactic acid bacteria. Int J Food Microbiol. 2007;114(1):30-5. doi:10.1016/j.jfoodmicro.2006.10.040.

37. Monachese M, Burton JP, Reid G. Bioremediation and tolerance of humans to heavy metals through microbial processes: a potential role for probiotics? Appl Environ Microbiol. 2012;78(18):6397-404. doi:10.1128/ aem.01665-12.

38. Curtis JT, Hood AN, Chen Y, Cobb GP, Wallace DR. Chronic metals ingestion by prairie voles produces sex-specific deficits in social behavior: an animal model of autism. Behav Brain Res. 2010;213(1):42-9. doi:10.1016/j. bbr.2010.04.028.

39. Mahenthiralingam E, Marchbank A, Drevinek P, Garaiova I, Plummer S. Use of colony-based bacterial strain typing for tracking the fate of Lactobacillus strains during human consumption. BMC Microbiol. 2009;9:251. doi:10.1186/1471-2180-9-251.

40. Bizhang M, Ellerbrock B, Preza D, Raab W, Singh P, Beikler T, et al. Detection of nine microorganisms from the initial carious root lesions using a TaqMan-based real-time PCR. Oral Dis. 2011;17(7):642-52. doi:10.1111/j.1601-0825.2011.01815.x.

41. Byun R, Nadkarni MA, Chhour KL, Martin FE, Jacques NA, Hunter N. Quantitative analysis of diverse Lactobacillus species present in advanced dental caries. J Clin Microbiol. 2004;42(7):3128-36. doi:10.1128/ JCM.42.7.3128-3136.2004.

42. O'Toole GA, Pratt LA, Watnick PI, Newman DK, Weaver VB, Kolter R. Genetic approaches to study of biofilms. Methods Enzymol. 1999;310:91-109.

43. McGraw LA, Young LJ. The prairie vole: an emerging model organism for understanding the social brain. Trends Neurosci. 2010;33(2):103-9. doi:10.1016/j.tins.2009.11.006.

44. National Research Council. Nutrient requirements of the vole. Nutrient Requirements of Laboratory Animals, Fourth Revised Edition. Washington, DC: The National Academies Press; 1995. pp. 144-8.

45. Lebeer S, Vanderleyden J, De Keersmaecker SC. Genes and molecules of lactobacilli supporting probiotic action. Microbiol Mol Biol Rev. 2008;72(4):728-64. doi:10.1128/mmbr.00017-08.

46. Klaenhammer TR, Azcarate-Peril MA, Altermann E, Barrangou R. Influence of the dairy environment on gene expression and substrate utilization in lactic acid bacteria. J Nutr. 2007;137(3 suppl 2):748S-50S.

47. Yamano T, Tanida M, Niijima A, Maeda K, Okumura N, Fukushima Y, et al. Effects of the probiotic strain Lactobacillus johnsonii strain La1 on autonomic nerves and blood glucose in rats. Life Sci. 2006;79(20):1963-7. doi:10.1016/j.lfs.2006.06.038.

48. Allison GE, Klaenhammer TR. Functional analysis of the gene encoding immunity to lactacin F, lafl, and its use as a Lactobacillus-specific, foodgrade genetic marker. Appl Environ Microbiol. 1996;62(12):4450-60. 
49. De Vuyst L, Leroy F. Bacteriocins from lactic acid bacteria: production, purification, and food applications. J Mol Microbiol Biotechnol. 2007;13(4):194-9. doi:10.1159/000104752.

50. Pridmore RD, Pittet AC, Praplan F, Cavadini C. Hydrogen peroxide production by Lactobacillus johnsonii NCC 533 and its role in anti-Salmonella activity. FEMS Microbiol Lett. 2008;283(2):210-5. doi:10.1111/j.1574-6968.2008.01176.x.

51. Lin WH, Yu B, Jang SH, Tsen HY. Different probiotic properties for Lactobacillus fermentum strains isolated from swine and poultry. Anaerobe. 2007;13(3-4):107-13. doi:10.1016/j.anaerobe.2007.04.006

52. Cabo ML, Braber AF, Koenraad PM. Apparent antifungal activity of several lactic acid bacteria against Penicillium discolor is due to acetic acid in the medium. J Food Prot. 2002;65(8):1309-16.

53. Köhler GA, Assefa S, Reid G. Probiotic Interference of Lactobacillus rhamnosus GR-1 and Lactobacillus reuteri RC-14 with the opportunistic fungal pathogen Candida albicans. Infect Dis Obstet Gynecol. 2012;2012:14 doi:10.1155/2012/636474

54. Alakomi HL, Skytta E, Saarela M, Mattila-Sandholm T, Latva-Kala K, Helander IM. Lactic acid permeabilizes gram-negative bacteria by disrupting the outer membrane. Appl Environ Microbiol. 2000;66(5):2001-5.

55. Verdenelli MC, Ghelfi F, Silvi S, Orpianesi C, Cecchini C, Cresci A. Probiotic properties of Lactobacillus rhamnosus and Lactobacillus paracasei isolated from human faeces. Eur J Nutr. 2009;48(6):355-63. doi:10.1007/ s00394-009-0021-2.

56. Ehrmann MA, Kurzak P, Bauer J, Vogel RF. Characterization of lactobacilli towards their use as probiotic adjuncts in poultry. J Appl Microbiol. 2002;92(5):966-75.

57. Kaushik JK, Kumar A, Duary RK, Mohanty AK, Grover S, Batish VK. Functional and probiotic attributes of an indigenous isolate of Lactobacillus plantarum. PLoS One. 2009;4(12):e8099. doi:10.1371/journal. pone.0008099.

58. Gotcheva V, Hristozova E, Hristozova T, Guo M, Roshkova Z, Angelov A. Assessment of potential probiotic properties of lactic acid bacteria and yeast strains. Food Biotechnol. 2002;16(3):211-25. doi:10.1081/ FBT-120016668.

59. Ibrahim F, Halttunen T, Tahvonen R, Salminen S. Probiotic bacteria as potential detoxification tools: assessing their heavy metal binding isotherms. Can J Microbiol. 2006;52(9):877-85. doi:10.1139/w06-043.

60. Risher JF. Elemental mercury and inorganic mercury compounds: human health aspects. Geneva: World Health Organization; 2003.

61. Robinson JB, Tuovinen $\mathrm{OH}$. Mechanisms of microbial resistance and detoxification of mercury and organomercury compounds: physiological, biochemical, and genetic analyses. Microbiol Rev. 1984;48(2):95-124.

62. Bisanz JE, Enos MK, Mwanga JR, Changalucha J, Burton JP, Gloor GB et al. Randomized open-label pilot study of the influence of probiotics and the gut microbiome on toxic metal levels in Tanzanian pregnant women and school children. MBio. 2014;5(5):e01580-14. doi:10.1128/mBio.01580-14.

63. Lebeer S, Verhoeven TL, Perea Velez M, Vanderleyden J, De Keersmaecker SC. Impact of environmental and genetic factors on biofilm formation by the probiotic strain Lactobacillus rhamnosus GG. Appl Environ Microbiol. 2007;73(21):6768-75. doi:10.1128/aem.01393-07.

64. Ambalam P, Kondepudi KK, Nilsson I, Wadstrom T, Ljungh A. Bile stimulates cell surface hydrophobicity, Congo red binding and biofilm formation of Lactobacillus strains. FEMS Microbiol Lett. 2012;333(1):10-9. doi:10.1111/j.1574-6968.2012.02590.x.
65. Lane DJ. 16S/23S rRNA sequencing. In: Stackebrandt E, Goodfellow M, editors. Nucleic acid techniques in bacterial systematics. New York: Wiley; 1991. p. 115-75.

66. DeSantis TZ, Hugenholtz P, Larsen N, Rojas M, Brodie EL, Keller K, et al. Greengenes, a chimera-checked 165 rRNA gene database and workbench compatible with ARB. Appl Environ Microbiol. 2006;72(7):5069-72. doi:10.1128/AEM.03006-05.

67. Garcia-Vallve S, Palau J, Romeu A. Horizontal gene transfer in glycosyl hydrolases inferred from codon usage in Escherichia coli and Bacillus subtilis. Mol Biol Evol. 1999;16(9):1125-34.

68. Lee DY, Seo YS, Rayamajhi N, Kang ML, Lee SI, Yoo HS. Isolation, characterization, and evaluation of wild isolates of Lactobacillus reuteri from pig feces. J Microbiol. 2009;47(6):663-72. doi:10.1007/s12275-009-0124-8.

69. Rupf S, Merte K, Eschrich K, Stosser L, Kneist S. Peroxidase reaction as a parameter for discrimination of Streptococcus mutans and Streptococcus sobrinus. Caries Res. 2001;35(4):258-64.

70. Li X, Yan Z, Xu J. Quantitative variation of biofilms among strains in natural populations of Candida albicans. Microbiology. 2003;149(Pt 2):353-62.

71. Fernandez MF, Boris S, Barbes C. Probiotic properties of human lactobacilli strains to be used in the gastrointestinal tract. J Appl Microbiol. 2003;94(3):449-55.

72. Wiegand I, Hilpert K, Hancock RE. Agar and broth dilution methods to determine the minimal inhibitory concentration (MIC) of antimicrobial substances. Nat Protoc. 2008;3(2):163-75. doi:10.1038/nprot.2007.521.

73. Gillum AM, Tsay EY, Kirsch DR. Isolation of the Candida albicans gene for orotidine-5'-phosphate decarboxylase by complementation of S. cerevisiae ura3 and E. coli pyrF mutations. Mol Gen Genet. 1984;198(1):179-82.

74. Holloway BW, Krishnapillai V, Morgan AF. Chromosomal genetics of Pseudomonas. Microbiol Rev. 1979:43(1):73-102.

75. Reid G, Charbonneau D, Erb J, Kochanowski B, Beuerman D, Poehner R, et al. Oral use of Lactobacillus rhamnosus GR-1 and L. fermentum RC-14 significantly alters vaginal flora: randomized, placebo-controlled trial in 64 healthy women. FEMS Immunol Med Microbiol. 2003;35(2):131-4. doi:10.1016/S0928-8244(02)00465-0.

76. Reid G, Cook RL, Bruce AW. Examination of strains of lactobacilli for properties that may influence bacterial interference in the urinary tract. J Urol. 1987;138(2):330-5.

77. Silva M, Jacobus NV, Deneke C, Gorbach SL. Antimicrobial substance from a human Lactobacillus strain. Antimicrob Agents Chemother. 1987;31(8):1231-3.

78. Turner S, Pryer KM, Miao VP, Palmer JD. Investigating deep phylogenetic relationships among cyanobacteria and plastids by small subunit rRNA sequence analysis. J Eukaryot Microbiol. 1999;46(4):327-38.

79. Baker GC, Smith JJ, Cowan DA. Review and re-analysis of domain-specific $16 S$ primers. J Microbiol Methods. 2003;55(3):541-55.

\section{Submit your next manuscript to BioMed Central and we will help you at every step:}

- We accept pre-submission inquiries

- Our selector tool helps you to find the most relevant journal

- We provide round the clock customer support

- Convenient online submission

- Thorough peer review

- Inclusion in PubMed and all major indexing services

- Maximum visibility for your research

Submit your manuscript at www.biomedcentral.com/submit

(O) BioMed Central 